\title{
1 Loss of HMCES is synthetic lethal with APOBEC activity in cancer cells
}

3 Josep Biayna ${ }^{1}$, Isabel Garcia-Cao ${ }^{2}$, Miguel M. Álvarez ${ }^{1}$, Marina Salvadores ${ }^{1}$, Jose Espinosa4 Carrasco ${ }^{1}$, Marcel McCullough ${ }^{1}$, Fran Supek ${ }^{1,3, *}$ and Travis H. Stracker ${ }^{2,4 *}$

${ }^{1}$ Genome Data Science, Institute for Research in Biomedicine (IRB Barcelona), The Barcelona Institute of Science and Technology, C/ Baldiri Reixac 10, Barcelona 08028, Spain.

92 Genomic Instability and Cancer, Institute for Research in Biomedicine (IRB Barcelona), The 10 Barcelona Institute of Science and Technology, C/ Baldiri Reixac 10, Barcelona 08028, 11 Spain.

$12{ }^{3}$ Catalan Institution for Advanced Studies (ICREA), Passeig de Lluís Companys, 23, 08010 13 Barcelona, Spain.

${ }^{4}$ National Cancer Institute, Center for Cancer Research, Radiation Oncology Branch, 10 Center Dr, Building 10, Bethesda, MD 20814, USA

*Lead contacts: fran.supek@irbbarcelona.org, travis.stracker@nih.gov

\section{Running title: HMCES is synthetic lethal with APOBEC expression}

Word count: abstract 199, introduction/results/discussion, figure legends, materials and methods 6101 words.

Key words: APOBEC, HMCES, synthetic lethality, lung cancer, CRISPR/Cas9 


\section{Abstract}

39 Analysis of cancer mutagenic signatures provides information about the origin of 40 mutations and can inform the use of clinical therapies, including immunotherapy. In

41 particular, $\mathrm{APOBEC} 3 \mathrm{~A}(\mathrm{~A} 3 \mathrm{~A})$ has emerged as a major driver of mutagenesis in 42 cancer cells and its expression results in DNA damage and susceptibility to 43 treatment with inhibitors of the ATR and CHK1 checkpoint kinases. Here we report

44 the implementation of CRISPR/Cas9 genetic screening to identify susceptibilities of 45 multiple A3A-expressing lung adenocarcinoma cell lines. We identify HMCES, a 46 protein recently linked to the protection of abasic sites, as a central protein for the 47 tolerance of A3A expression. HMCES depletion results in synthetic lethality with A3A 48 expression specifically in a TP53-mutant background. Analysis of previous 49 screening data reveals a strong association between A3A mutational signatures and sensitivity to HMCES loss and indicates that HMCES is specialized in protecting

51 against a narrow spectrum of DNA damaging agents in addition to $\mathrm{A} 3 \mathrm{~A}$. We experimentally show that both HMCES disruption and A3A expression increase

53 susceptibility of cancer cells to ionizing radiation, oxidative stress and ATR inhibition;

54 strategies that are often applied in tumor therapies. Overall, our results suggest that 55 HMCES is an attractive target for selective treatment of A3A expressing tumors.

\section{Introduction}

58 The APOBEC3 (apolipoprotein B mRNA-editing enzyme catalytic polypeptide-like 3)

59 family of cytidine deaminases is a major source of mutagenesis in human cancers. 60 Elevated mRNA levels of APOBEC3A (A3A) and APOBEC3B (A3B) enzymes, as 
61 well as an activating germline polymorphism in the $A 3 A$ and $A 3 B$ genes, were

62 associated with a particular mutational signature of C-to-T and C-to-G changes in a

63 TW trinucleotide context (where $\mathrm{W}$ is $\mathrm{A}$ or $\mathrm{T})[1-4]$. Both $\mathrm{A} 3 \mathrm{~A}$ and $\mathrm{A} 3 \mathrm{~B}$ have been

64 implicated in localized hypermutation, which can occur in two different patterns: the

65 focused kataegis ('mutation showers', likely occurring during repair of DNA double-

66 strand (ds) breaks (DSB)[1,5]) and the diffuse omikli pattern ('mutation fog',

67 proposed to occur during repair of mismatched or damaged nucleotides[6,7]. The

68 A3s are a cause of intratumor genetic heterogeneity and generate driver mutations

69 in tumors[7-10]. Consistently, A3 mutagenesis has prognostic value in

70 cancers[1,11-13]. Recent genomics work suggests that A3 mutagenesis appears

71 rare in various types of apparently non-cancerous somatic cells[14], and moreover

72 A3 mutagenesis appears to increase in intensity in metastatic cancers[15]. This

73 suggests that vulnerabilities of APOBEC-expressing cells would provide a window

74 of opportunity to selectively target certain types of tumor cells while sparing their

75 healthy counterparts.

77 Overexpressing A3 enzymes in yeast and human cell lines results in clustered

78 mutation patterns resembling those seen in cancer genomes[13,16,17]. Therefore,

79 such experimental models of A3 overexpression appear useful for recapitulating

80 DNA damaging and mutagenic effects that occur in tumors due to APOBEC activity.

81 The $A 3 A$ mutagenesis signature is distinguishable from that of $A 3 B$ and both

82 signatures are present in varying proportions across cancer types. However, the A3A

83 signature is predominant overall[7,18-21] consistent with experiments suggesting 
84 that A3A induces high levels of DNA damage[2,22]. We therefore focused our

85 attention on $\mathrm{A} 3 \mathrm{~A}$.

86

87 A3s deaminate cytosine in DNA to generate uracil, which can be converted to an abasic (AP) site, following the action of uracil glycosylases[23]. Uracil is mutagenic, causing U:G mispairing during copying. Moreover, AP-sites cannot be directly copied by the replicative DNA polymerases during S-phase, necessitating the use of

91 potentially mutagenic translesion synthesis (TLS) polymerases[24]. A3A induced

92 damage occurs during S-phase and AP-sites can lead to replication fork stalling and 93 replication stress[25-27]. Processing of AP-sites by AP-endonucleases can allow 94 repair by the base excision repair $(B E R)$ pathway. This can promote further $A 3$ mutagenesis, particularly if coupled with the activity of DNA mismatch repair that can

96 'hijack' BER intermediates[6]. Alternatively, the processing of AP-sites in ssDNA can 97 convert them to DNA double-strand breaks (DSBs), a more cytotoxic lesion.

98 Processing and repair of DSBs by the homologous recombination (HR) or break99 induced replication (BIR) pathways generates additional ssDNA which may be 100 targeted by APOBECs[5,28]. Thus, multiple DNA repair pathways are engaged as a 101 consequence of A3-induced DNA damage, and activity of these pathways can 102 promote further A3 DNA damage.

104 Increased reliance of some tumors on particular DNA repair pathways has long been 105 exploited as a therapeutic avenue. For example, brain cancers that lose activity of 106 the 0-6-methylguanine-DNA methyltransferase (MGMT) enzyme, that can directly 107 reverse O-6 adducts, are more sensitive to the DNA methylating drug temozolomide 
108 (TMZ)[29]. Ovarian and breast tumors with failures in HR repair pathways due to

109 inactivated BRCA1 and BRCA2 genes are more sensitive to PARP inhibitors, such

110 as Olaparib[30,31]. These examples of successful therapeutic applications

111 encouraged us to search for targetable DNA repair pathways in cancer cells exposed

112 to increased A3A activity.

114 Overexpression of A3A causes DNA damage and replication stress; the latter can

115 be targeted by inhibitors of the ATR and CHK1 checkpoint kinases that respond to 116 replication stress[22,32,33]. The observation that cell cycle checkpoint inhibitors

117 enhanced the levels of DNA damage in A3A-expressing cells indicates that it is 118 plausible that they have many additional inherent vulnerabilities that can be 119 therapeutically exploited, apart from the replication stress response, which is a more 120 general phenomenon not specific to A3A.

122 We performed a CRISPR/Cas9-based genome-wide screen for genes required to 123 tolerate A3A-mediated DNA damage in a panel of cell lines from non-small cell lung 124 cancer (NSCLC), where APOBEC activity has been shown to play an important role 125 in tumor evolution[3,4,34-36]. Among other hits, we identified factors involved in 126 multiple DSB repair pathways, including RAD9A, a component of the 9-1-1

127 alternative clamp loader and the recently characterized MCM8-MCM9-HROB 128 complex[37-40]. Crucially, we found that different genetic backgrounds are 129 consistently and strongly dependent on the gene encoding HMCES (5hmC binding, 130 embryonic stem cell-specific-protein) for cell viability[8,15] under APOBEC stress, 131 but not otherwise. Recently, HMCES (also known as SRAP Domain-containing 
132 Protein 1), as well as the related bacterial protein YedK, were shown to covalently

133 bind to AP-sites in ssDNA, where they act as a suicide enzyme to protect them from

134 TLS or AP-endonucleases[41-46]. In addition, HMCES has been proposed to

135 function in the repair of DSBs in the canonical and the alternative non-homologous

136 end-joining (NHEJ) pathways[42,47,48]. We validated HMCES depletion as a

137 sensitizer to A3A in multiple cell lines, consistent with recent work[49], and show that

138 HMCES limits DNA damage and prevents loss of cell viability resulting from $A 3 A$

139 expression in a manner specific to TP53-mutant cells. Together, our results identify

140 additional druggable targets to be considered in A3A expressing cancer cells and

141 establish a central role for HMCES in preventing the toxicity of A3A expression.

\section{Results}

144 Generation of non-small cell lung cancer cell lines with inducible A3A

\section{expression}

146 To examine the influence of A3A expression in NSCLC, we established a panel of

147 cell lines with doxycycline (DOX) inducible expression of a haemagglutinin (HA)-

148 tagged-A3A using the pSLIK-Neo vector system (Fig 1A-1B)[27]. This included $\mathrm{NCl}$ -

149 H358, LXF-289, A549 and a TP53 null variant of A549, A549 ${ }^{\text {TP53--/, }}$, generated using

150 CRISPR/Cas9 targeting (S1 Fig). Treatment of cells with DOX resulted in a dose-

151 dependent increase in A3A mRNA expression and protein levels (Fig 1A-1B).

152 Consistent with previous reports that A3A expression caused DNA damage and cell

153 cycle checkpoint activation, we observed a slower growth rate in several of the

154 NSCLC cell lines (Fig 1C)[27]. 

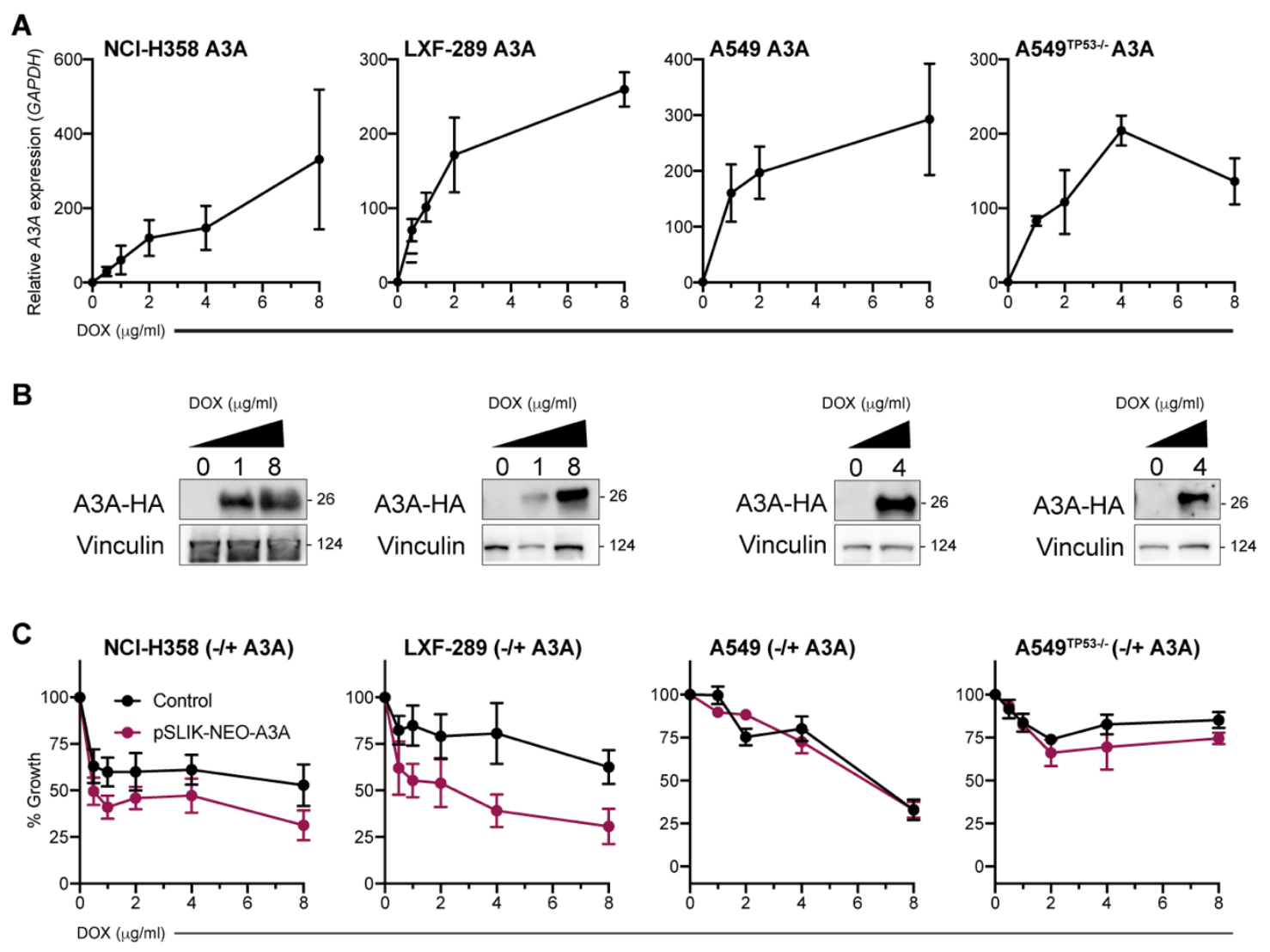

156 Fig 1. Inducible A3A expression reduces the fitness of lung adenocarcinoma

157 cell lines. (A) A3A mRNA levels in NCl-H358, LXF-289, A549 and A549TP53-- cell

158 lines transduced with a doxycycline (DOX) inducible A3A cassette at various 159 concentrations of DOX. Quantitative real-time PCR (qRT-PCR) and western blot 160 analysis were repeated two times. (B) Western blot detection of HA-A3A upon DOX 161 induction. LXF-289, NCl-H358, A549 and A549 ${ }^{\text {TP53-l- }}$ cells were collected and lysed

$16272 \mathrm{~h}$ post-treatment. Vinculin serves as a loading control and molecular weight (MW)

163 is indicated in kilodaltons. (C) Growth (percentage of growth rate relative to the cells

164 without DOX) for the indicated cell lines after $72 \mathrm{~h}$ of DOX treatment measured with 165 alamarBlue. In red, cells transduced with the inducible A3A cassette and in black, 
166 the parental cell line (no A3A) exposed to the same concentration of DOX. Growth

167 assays were repeated three times. For all graphs, mean and SEM are shown.

168

169 CRISPR/Cas9 genetic screen for A3A synthetic lethality

170 In order to identify vulnerabilities of A3A expressing cells, we performed genome-

171 wide CRISPR/Cas9 screening in three lung adenocarcinoma cell lines: LXF-289,

172 A549 and A549 ${ }^{\text {TP53-I- }}$. Screening was performed at an established IC $_{25}$ dose of DOX

173 for A549 and A549 ${ }^{\text {TP53--- }}$ and IC $_{25}$ and IC $_{50}$ doses for LXF-289 (Fig 2A). The cell lines,

174 with or without pSLIK-Neo A3A, were transduced with a single-vector lentiviral library

175 expressing Cas9 (Brunello) and guide RNAs (gRNAs) for 19,114 genes (4 single

176 gRNAs (sgRNAs) per gene) at a multiplicity of infection (MOI) $\leq 0.4$ (Fig. 2A)[50].

177 Following puromycin selection, cells were lysed, genomic DNA extracted and

178 preparation and analysis of initial gRNA representation (T0) was performed. Cells

179 were subsequently expanded for 15 days and treated with DOX to induce A3A

180 expression. At multiple time points following DOX treatment, we collected cells and

181 amplified guide DNAs (gDNAs) using barcoded primers. DNA was sequenced and

182 analyzed for changes in abundance of gDNAs targeting various genes, comparing

183 the DOX-treated cells with the untreated (control) cell line at the same time point

184 using the MAGeCK-RRA tool[51], thus revealing genes which have stronger fitness

185 effects in A3A expressing cells. Additionally, we compared to T0 to determine overall

186 essential genes. The control experiment showed that DOX itself (in a genetic

187 background lacking the A3A plasmid) affected the essentiality of very few genes (S2

188 Fig). 
190 As TP53 status has been shown to influence CRISPR/Cas9 screening results, we

191 first compared A549 ${ }^{\text {TP53--/ }}$ with the LXF-289 cell line that bears a TP53 mutation

192 (c.742C>T; p.R248W per DepMap.org record ACH-000787) (Fig 2B)[52]. We

193 prioritized genes by an overall APOBEC essentiality score: average $\log _{2}$ fold-change

194 (LFC) over six measurements: three time points for the A549 ${ }^{\text {TP53-/- }}$ cell line (T9, T12

195 and T15) and three for the LXF-289 cell line (T5, T10 and T15). The top five hits by

196 this score were the genes coding for the AP-site protecting protein HMCES[42], the

197 RAD9A cell cycle checkpoint control protein, the MCM8 component of the MCM8-

198 MCM9-HROB complex[37,38,53], ATXN7L3, a component of the SAGA chromatin

199 modifying complex[54,55], and HGC6.3, an uncharacterized protein. For four of the

200 five genes, the individual gRNAs, four per gene, consistently sensitized cells to A3A

201 expression (Fig 2B and S3 Fig). However, HGC6.3 guides displayed an inconsistent

202 temporal trend and the effect size for HGC6.3 was very different across the two cell

203 lines (S3 Fig). An additional analysis by the MAGeCK-MLE method[51] (S4 Fig)

204 suggested that all four gRNAs for HGC6.3 had low knockout efficiency (all <=0.72;

205 (S1 Table)) in contrast to other top hits, and we thus disregarded HGC6.3 in further

206 analysis. The remaining four top hits did not show clear differences in effects

207 between the two tested A3A dosages in the LXF-289 cell line (corresponding to $I_{25}$

208 and $\mathrm{IC}_{50}$ ) (Panel D in S3 Fig). Next highest-ranking hits included the UBA6 ubiquitin

209 activating enzyme, and a further five genes that were all related to DNA repair, DNA

210 replication or cell cycle control (DDX11, MCM9, CDC23, MAD2L2 (also known as

211 REV7), and HROB (also known as C17orf53 or MCM8IP; S1 Table). 
213 Distinct genes but consistent pathways in A3A responses across genetic

\section{4 backgrounds}

215 We further examined global trends in response to A3A expression across all 19,000

216 genes and twelve different experimental conditions, using principal components

217 (PC) analysis (Fig 2C). This suggested that globally, the results differ considerably

218 between the A549 and LXF-289 cell lines, indicating that the genetic background 219 modulates conditional essentiality of many genes under A3A conditions (data for top

220 hits shown in S5 Fig). In particular, the first two PCs explained 34\% variability in the

221 data and separated the LXF-289 from the A549 cell line data points, but they did not

222 appreciably separate (i) the three different time points within each cell line, nor (ii)

223 the TP53 wild-type versus TP53-/- background of the A549 cell line, nor (iii) the two

224 different $\mathrm{A} 3 \mathrm{~A}$ doses $\left(\mathrm{IC}_{25}\right.$ and $\left.\mathrm{IC}_{50}\right)$ in the $\mathrm{LXF}-289$ cell line. The same $\mathrm{PC}$ analysis

225 highlighted two genes with an extremely strong signal in the A3A response: HMCES,

226 because it is consistently observed across both genetic backgrounds (Fig 2C), and

227 the LXF-298-specific HGC6.3 gene, which we suspect is an artefact (see above).

228 We further substantiated these results using MAGeCK-MLE[51]; in this analysis,

229 HMCES was the only gene which was conditionally essential (>2 standard deviations

230 away from the mean of the beta coefficients, per MAGeCK-MLE recommendation)

231 in late time-point samples in both A549 ${ }^{\text {TP53-I- }}$ and LXF-289 cells (S4 Fig).

232

233 Despite the apparent differences in the effects of individual genes between A549TP53-

$234^{\text {I- }}$ and LXF-289 cells (S2 Table), Gene Ontology analysis yielded consistent results

235 (Fig 2D), identifying DNA repair-related pathways as strongly enriched. In both cell

236 lines, DSB repair was a major enriched biological process, with homologous 
237 recombination (HR) representing the predominant pathway, and to a lesser extent,

238 interstrand crosslink (ICL) repair (at $p<10^{-3}$ using the GORILLA server; see S3 Table

239 for list of results). Furthermore, nucleotide excision repair (NER) and DNA mismatch

240 repair (MMR) were enriched in both cell lines, as well as the regulation of the cell

241 cycle (Fig 2D and S3 Table). In LXF-289 cells, the non-homologous end-joining

242 (NHEJ) and Fanconi anemia pathways were strongly represented among the top hits

243 enriched, as well as MCM8, MCM9 and $H R O B$, genes that have previously been

244 implicated in HR (Fig 2D and S3 Table)[37,38,53]. Further enriched pathways related

245 to DNA repair included error-prone TLS and telomere maintenance in LXF-289 cells.

246 Intriguingly, there was also a strong enrichment of mRNA splicing genes (S3

247 Table). In A549 ${ }^{\text {TP53-- }}$ cells, there was also enrichment of DSB repair via synthesis-

248 dependent strand annealing (SDSA) (Fig 2D and S3 Table). Overall, we conclude

249 that A3A expression induces dependencies on a variety of DNA repair and related

250 pathways in cells, some of which may be specific to certain genetic backgrounds,

251 while others appear more universal. 
bioRxiv preprint doi: https://doi org/101101/2021.02 05.429803: this version posted February 6 , 2021. The copyright holder for this preprint (which was not certified by peer review) is the author/funder, who has granted bioRxiv a license to display the preprint in perpetuity. It is made available under aCC-BY-NC 4.0 International license.

A

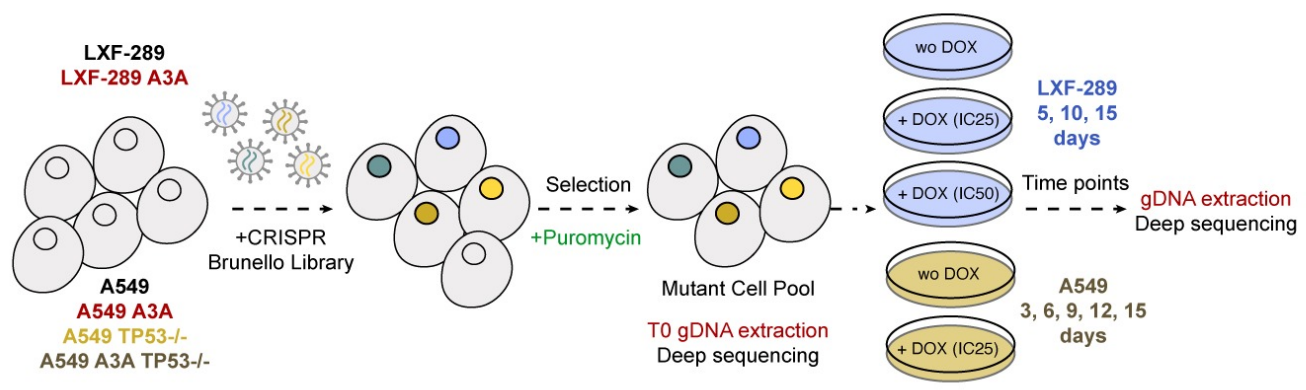

B

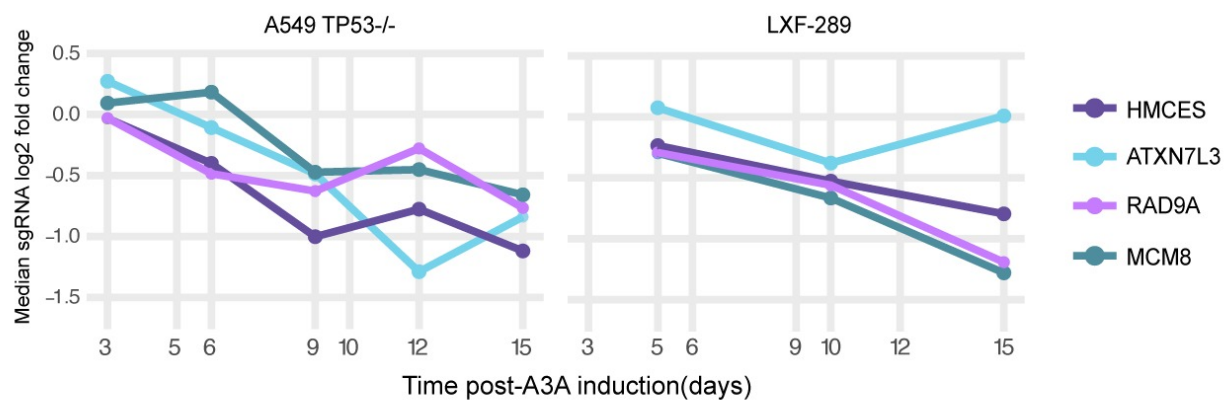

C

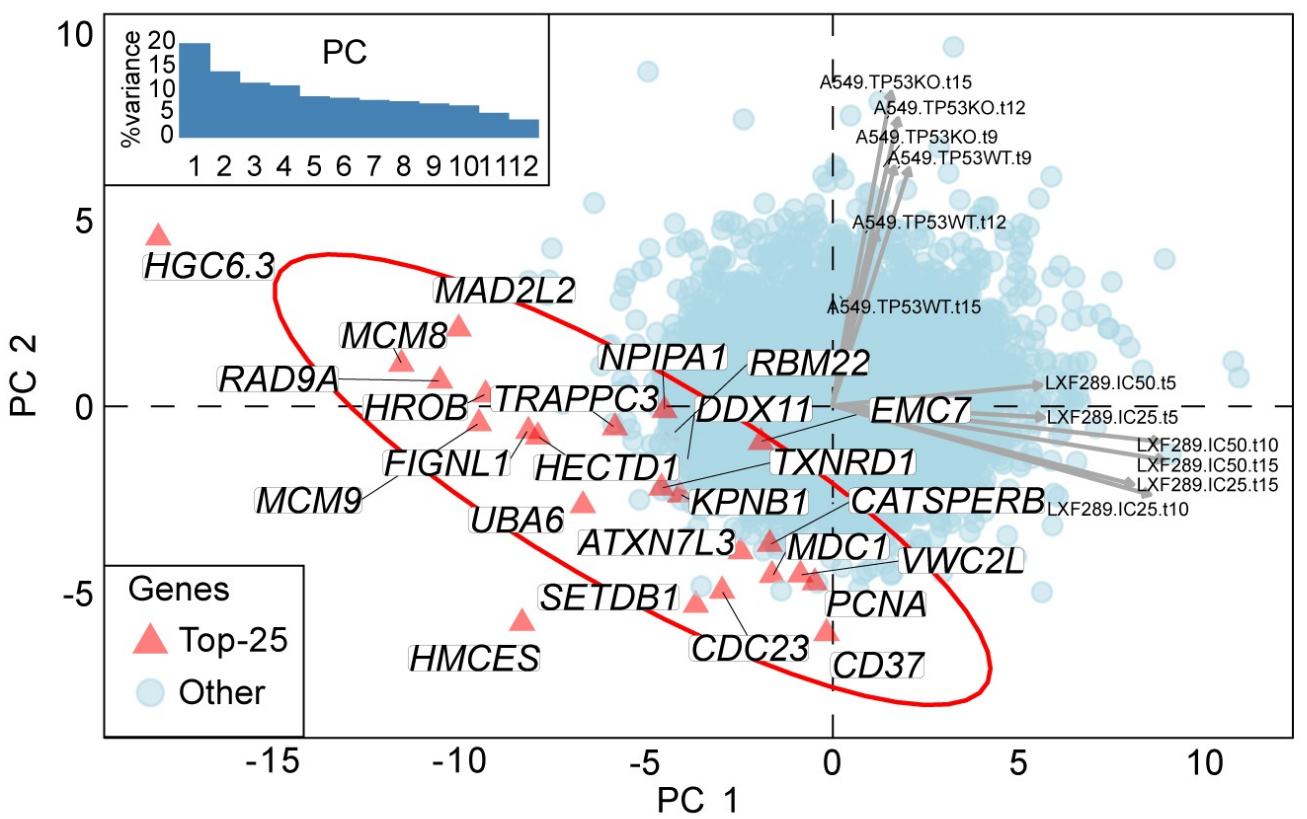

D

D Biological processes

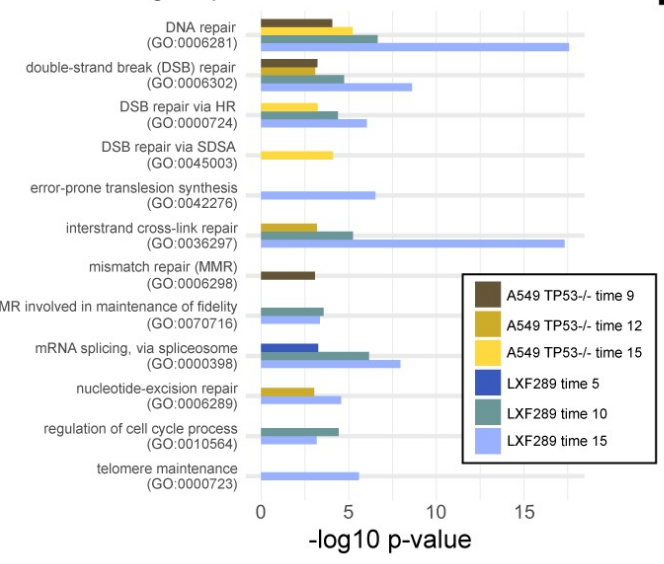

E Cell Cycle

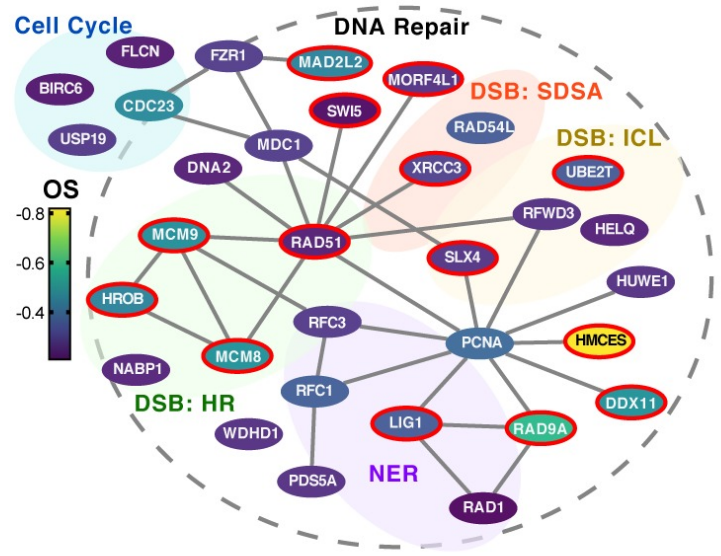


253 Fig 2. CRISPR/Cas9 genetic screen indicates HMCES and other DNA repair

254 genes as vulnerabilities of A3A expressing cells. (A) Experimental design using

255 the Brunello genome-wide library[50]. (B) Depletion of the sgRNAs targeting top four

256 genes upon A3A overexpression, as prioritized by the overall A3A conditional

257 essentiality score: LFC across three time points of the LXF-289 cell line and the three

258 latest time points of the A549 ${ }^{\text {TP53-I- }}$ cell line. $y$-axis shows the median of the four

259 sgRNAs per gene. (C) Principal component (PC) analysis of A3A-conditional LFC

260 scores for all genes across all 12 experimental conditions (see labels next to arrows,

261 which show loadings of the conditions on PC1 and PC2; "KO" implies TP53-/- and

262 "WT" TP53 wild-type A549 cell line; numbers in labels are the time points; "IC25"

263 and "IC50" are two concentrations of DOX in the LXF-289 cell line). The top 25

264 genes, prioritized by the same A3A conditional score as in panel B are highlighted

265 on the figure. Inlay shows a scree-plot, with the amount of variance explained by the

26612 PCs. The LXF-289-specific HGC6.3 hit is likely an artefact (see Results text).

267 Scores for all genes/sgRNAs are included in S2 Table. (D) Gene Ontology

268 enrichment analysis of the top hits in the six experiments considered for the overall

269 A3A conditional score (as in panel B). Plot shows -log10 p-value (unadjusted) from

270 the GORILLA server; $p>10^{-3}$ are not shown. Additional information in S3 Table. (E)

271 Network schematic of cell cycle and DNA repair-related genes from the top 300 hits

272 in the screen (overall score: OS). Genes identified in the Gene Ontology analysis

273 and appearing in the top 300 genes by OS are shown. Color denotes the OS, lines

274 indicate physical interactions (thebiogrid.org)[56] and a red border indicates they

275 were identified in the Gene Ontology analysis in both cell lines. 
277 Analyses of large-scale genetic screening data suggest a unique role of

278 HMCES

279 Our genetic screens performed in different cancer cell lines yielded many A3A

280 conditionally essential genes that were specific to one of the two cell lines (Fig 2C).

281 Quality control parameters of the screening data indicated the high quality of all the

282 screens by gDNA representation, by the ability to discriminate common essential

283 genes, and by the separation between APOBEC conditionally essential genes and

284 non-targeting, control sgRNAs (S6 Fig and S4 Table). Therefore, a likely explanation

285 for the differences between cell lines could be that the genetic background and/or

286 epigenetic state of a cell line determines its complement of essential genes upon

287 A3A activation.

This motivated us to seek further evidence that the top hits we observed across both cell lines would indeed be valid across a wider spectrum of genetic backgrounds. To

291 this end, we analyzed data from 76 lung adenocarcinoma, lung squamous cell 292 carcinoma and head and neck squamous cell carcinoma cell lines (thus 293 approximately matching our experimental models by tissue or cell type) from the 294 Project Achilles database[57,58]. In particular, we searched among the top 10 genes 295 from our experiments for correlations between the burden of A3 context mutations 296 in the cell line exomes and the essentiality of a gene. By this metric, the HMCES 297 gene obtained the highest scores in the external Project Achilles data (Fig 3A and 298 S5 Table) for APOBEC signature 13 and signature 2 (slope of fit -0.29 and -0.5 , 299 respectively; combined $p=0.03$, t-test on the regression coefficient, one-tailed). In 300 contrast, the MCM8, RAD9A and ATXN7L3 genes, even though observed in both 
301 cell lines in our experiments, did not score highly in this analysis (Fig 3A; we note

302 that MCM8 does rank more highly than other top hits from the genetic screen, but is

303 nonetheless not robustly supported; S5 Table). This provided additional confidence

304 that the synthetic interaction between HMCES and A3 activity is likely to hold across

305 very diverse genetic backgrounds, as it is observed across a large cell line panel. A

306 caveat of this analysis is that the A3 mutational signature may reflect past activity or

307 intermittent activity of $\mathrm{A} 3$, and thus the lack of correlation in this analysis does not

308 necessarily rule out the validity of the hit.

310 In addition to HMCES, the analysis of our genetic screening data revealed many

311 common hits participating in DSB repair (Fig 2E). While it is likely that AP-sites

312 resulting downstream of APOBEC lesions may generate DSBs in need of repair,

313 such hits in the screen would plausibly also result from other agents inducing DSBs.

314 Because our screening effort is focused on finding potentially actionable

315 vulnerabilities, we were less interested in finding hits that result from DNA damaging

316 conditions in general, which may abundantly occur also in healthy cells and are not

317 linked to a genetic marker, in contrast to APOBEC activity, which may be more

318 common in tumors and is evident in mutational signatures. We therefore analyzed

319 data from previous genetic screens performed in the RPE1-TP53-- cell line under a

320 variety of different genotoxic agents[59]. We found that some of the common hits for

$321 \mathrm{~A} 3 \mathrm{~A}$ are also sensitizers in these genetic screens. For example, RAD9A loss

322 sensitizes to a variety of agents including gemcitabine, hydroxyurea, bleomycin,

323 AZD6738 (ATR inhibitor) and others (Fig 3B). MCM8, MCM9 or HROB loss

324 sensitized to MNNG, cisplatin, MMS, trabectedin and camptothecin (Fig 3B). Loss 
325 of the DDX11 helicase or MAD2L2 (also known as REV7, component of the shieldin

326 complex and accessory subunit of the error-prone DNA polymerase zeta) sensitized

327 to a wide gamut of DNA damaging agents tested (Fig 3B). This suggests these hits

328 may be generally critical to stalled forks, rather than specific to A3A-mediated

329 damage[6,59-61].

331 In contrast, HMCES, UBA6 and ATXN7L3 appeared to have a more restricted

332 pattern of sensitization to DNA damaging agents (Fig 3B), indicating that they may

333 represent better targets for selective killing of APOBEC expressing cancer cells. Of

334 those, HMCES exhibited a distinctive pattern that did not cluster with the other top-

33550 hits in our screen (Fig 3B). HMCES loss sensitized to exposure to $\mathrm{KBrO}_{3}$ and

$336 \mathrm{H}_{2} \mathrm{O}_{2}$ (oxidizing agents), and ionizing radiation (IR), that generates oxidative base

337 damage and DSBs, in previous data[59]. This is consistent with the occurrence of

338 AP-sites as repair intermediates of oxidatively damaged DNA and a role for HMCES

339 in protecting such AP sites. Intriguingly, HMCES loss also sensitized to illudin-S and

340 duocarmycin, alkylating drugs with incompletely understood mechanisms-of-action,

341 but less so to other alkylators (Fig 3B and S7 Fig)[59]. Overall, this joint analysis of

342 previous genetic screening data under DNA damaging conditions, together with our

343 APOBEC screens, indicates that HMCES has a specialized, rather than a general

344 role in protecting against DNA damage. Further, this suggests that inhibiting HMCES

345 would be selective for treating tumors undergoing certain types of DNA damage,

346 such as APOBEC-mediated cytosine deamination, or in combination with specific

347 therapeutic strategies, such as radiotherapy that is widely used in cancer treatment. 
A
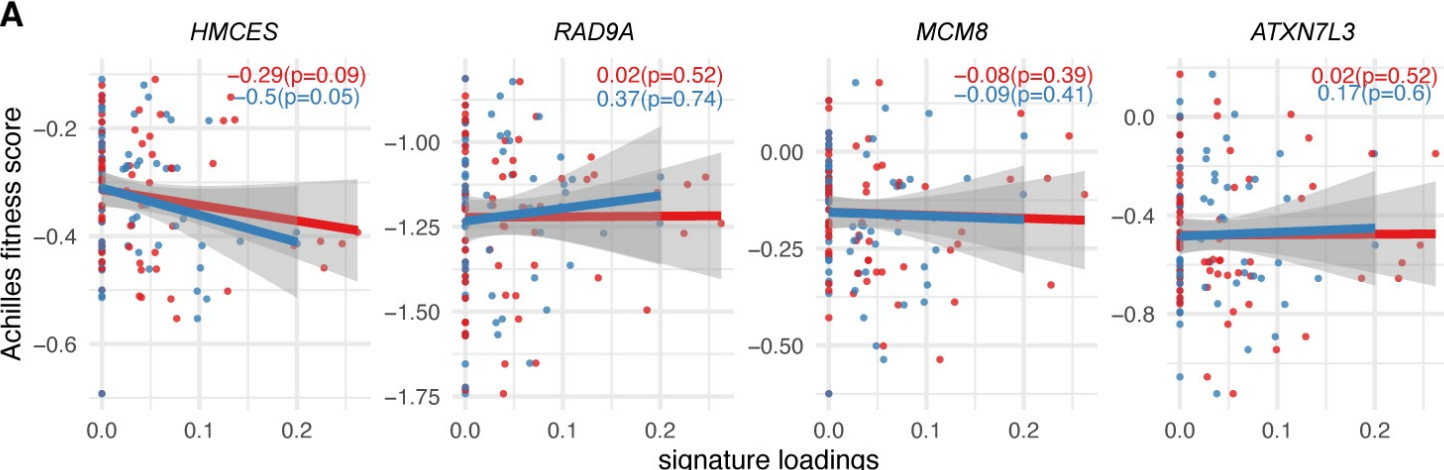

- signature $13=$ signature 2

B Biayna et al. screens Olivieri et al. screens

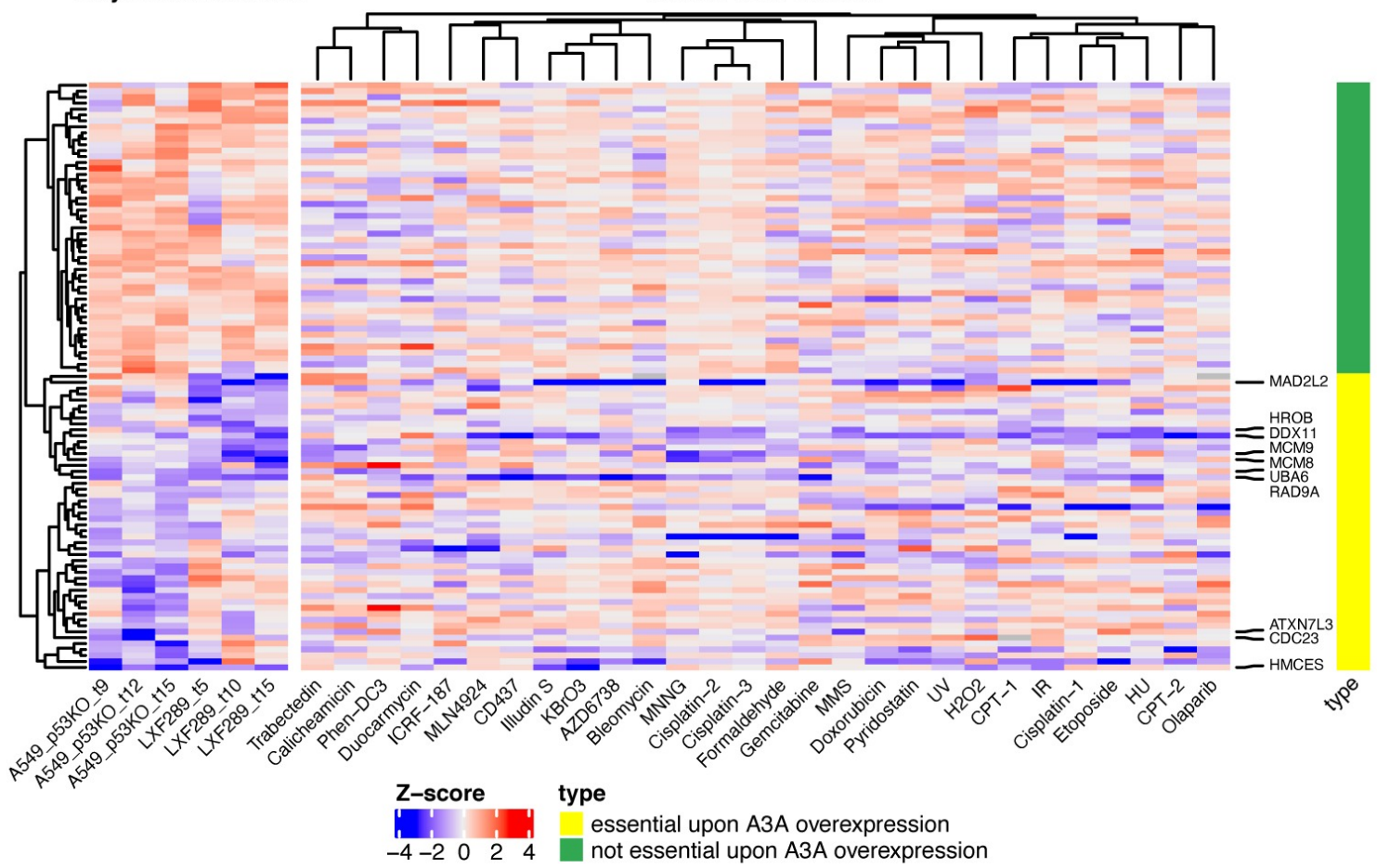

351 Fig 3. Dependency on HMCES is associated with mutational signatures of 352 APOBEC across 76 lung and head-and-neck cancer cell lines. (A) Gene 353 essentiality fitness score from Project Achilles versus APOBEC mutational

354 signatures exposures, for cell lines from head-and-neck squamous cell carcinoma, 
355 lung adenocarcinoma, and lung squamous cell carcinoma, in four of the genes with

356 the greatest overall score in our screens; see S5 Table and S8 Fig for associations

357 with additional prominent genes. The slope and p-value (one-tailed, lower) for the

358 regression model for both $\mathrm{A} 3$ signatures are shown within each panel. The more

359 negative the slope the more sensitive the cell lines are to the depletion of the gene

360 at a higher level of the APOBEC signature. (B) Heatmap shows a gene-level

361 normalized log2 fold change (gene essentiality score) upon A3A overexpression for

362 two cell lines and for three time points (Biayna et al. screens [59]); right panel shows

363 Z-scores of gene essentiality after genotoxin exposure (Olivieri et al. screens). Data

364 for 50 genes that are essential upon A3A overexpression in our screens (i.e. genes

365 with the most negative mean log2 fold change across six data points) and 50 non-

366 essential genes upon A3A overexpression in our screens. Labels on the right-hand

367 side highlight the ten genes showing the highest overall A3A essentiality. An

368 extended heatmap showing all genes from certain DNA repair pathways is included 369 in S7 Fig.

371 HMCES depletion sensitizes A3A expressing cells

372 To test these possibilities, we depleted HMCES in multiple lung cancer cell line 373 backgrounds by shRNA depletion or CRISPR/Cas9 knockout. Efficient depletion of 374 HMCES mRNA and protein levels by shRNA in either LXF-289 or NCl-H358 (Fig. $3754 \mathrm{~A}$ ), which was not used for the screening, enhanced sensitivity to A3A expression 376 to different extents. Sensitivity in LXF-289 cells was apparent at early and late times

377 (Fig. 4B), consistent with screening results, and accompanied by an arrest in G2/M 378 phase (Fig. 4C) and increased levels of the $\gamma \mathrm{H} 2 \mathrm{AX}$ DNA damage marker (Fig. 4D). 
$379 \mathrm{NCl}-\mathrm{H} 358$ cells also showed increased sensitivity to A3A expression (Fig. 4E).

380 Together with the A549 screening data, these experiments further support that

381 HMCES loss is more toxic to A3A-overexpressing cells in multiple genetic

382 backgrounds.

384 We next asked whether the top hits in our A3A genetic screen were dependent on

385 the activity of TP53, by comparing the derived A549TP53-/- cell line with its progenitor

386 A549 that has a wild-type TP53 status. Most of the top hits from the initial assay

387 were not among the genes that differed depending on TP53 status in A549. A

388 prominent exception was HMCES (S5 Fig), which exhibits a stronger loss of fitness

389 phenotype upon A3A expression in TP53-- cells than in wild-type cells (we also noted

390 some signal for CDC23; S5 Fig). As further support of this, in the statistical analysis

391 of previous genetic screening data from Project Achilles (Fig 3A), we found that the

392 association between the APOBEC mutational signatures and sensitivity to HMCES

393 loss holds only for the TP53 mutant cell lines, but not for the TP53 wild-type cell lines

394 (S9 Fig). To further test the epistatic interaction between TP53 and HMCES under

395 A3A expression, we directly assessed survival using colony forming assays in the

396 A549 cell line pair following A3A expression and HMCES depletion. This showed

397 that A549 ${ }^{\text {TP53--/ }}$ cells were more sensitive to A3A than A549 following HMCES

398 depletion with shRNA (Fig 4F). This suggests that HMCES inhibition could be used

399 to target A3A-expressing cells that have lost TP53, as is the case in many tumors,

400 while sparing TP53 wild-type cells to a large extent. 
402 Given that our experimental models rely on the inducible expression of exogenous

$403 A 3 A$, we wanted to ascertain the relevance of these results to endogenous $A 3 A$

404 expression levels in cancer cells. We examined endogenous $A 3 A$ expression by

405 qRT-PCR (Fig 4G) indicating that LXF-289 cells do not express detectable levels of

$406 A 3 A$, while $\mathrm{NCl}-\mathrm{H} 358$ cells do. We titrated our DOX levels down to achieve an

407 induction of $A 3 A$ mRNA levels in LXF289 cells similar to that of endogenous $A 3 A$

408 that we observed in $\mathrm{NCl}-\mathrm{H} 358$ cells (Fig 4G). We then examined the effect on cell

409 growth and found that this impaired the growth of LFX-289 when HMCES was

410 depleted (Fig 4H), consistent with experiments using higher DOX levels (Fig 4B). To

411 further address the issue of applicability of HMCES inhibition to endogenous $A 3 A$

412 levels, we examined public data for gene expression and mutational signatures in

413 other NSCLC cell lines, highlighting two contrasting examples: HCC-78, that express

414 A3A and exhibit APOBEC mutational signatures SBS2 and SBS13 (S10 Fig) [62,63],

415 and $\mathrm{NCl}-\mathrm{H} 2122$, that do not express detectable $A 3 A$ nor exhibit the A3-mutational

416 signatures (S10 Fig). We confirmed their relative A3A expression by qRT-PCR (S10

417 Fig) and depleted HMCES using shRNA. While both cell lines showed reduced levels

418 of HMCES protein, only the naturally A3A-expressing HCC-78, but not the A3A non-

419 expressing $\mathrm{NCl}-\mathrm{H} 2122$, showed significant defects in cell growth upon HMCES

420 depletion (Fig 4I). Together these data further support a role for HMCES in tolerating

421 endogenous $A 3 A$ expression in cancer cells. 
bioRxiv preprint doi: https://doi.org/10.1101/2021.02.05.429803; this version posted February 6, 2021. The copyright holder for this preprint (which was not certified by peer review) is the author/funder, who has granted bioRxiv a license to display the preprint in perpetuity. It is made available under aCC-BY-NC 4.0 International license.

A
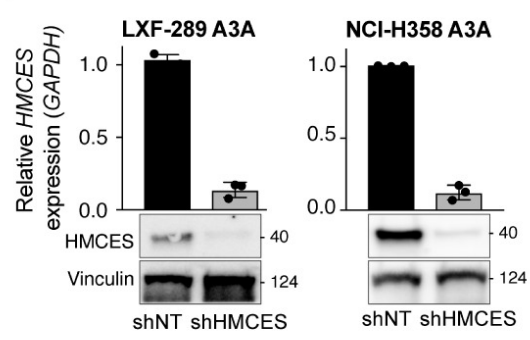

C
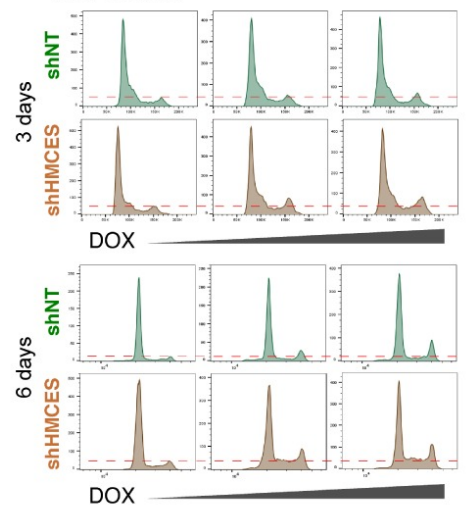

E

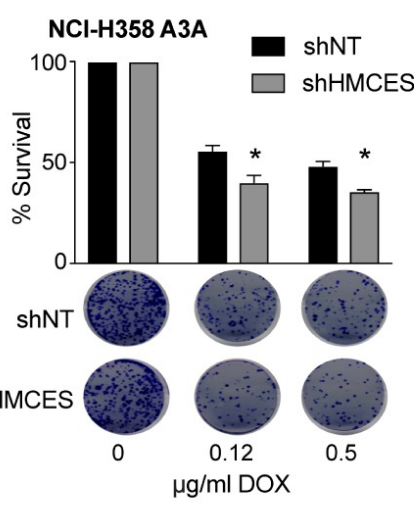

B LXF-289 A3A

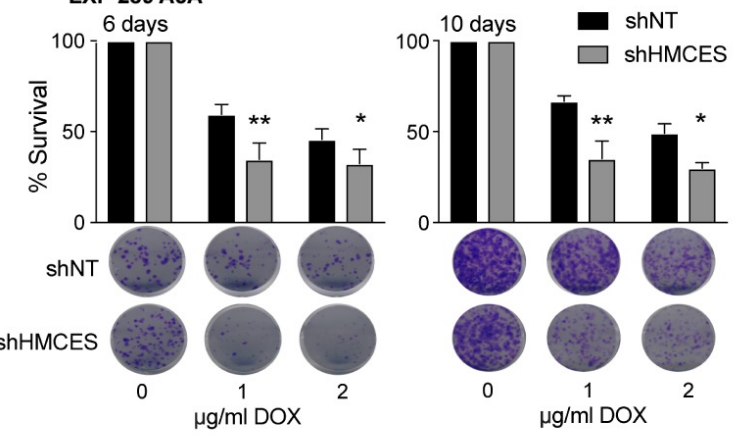

- G0/G1 $\square \mathrm{s} \square \mathrm{G} 2 \mathrm{M}$
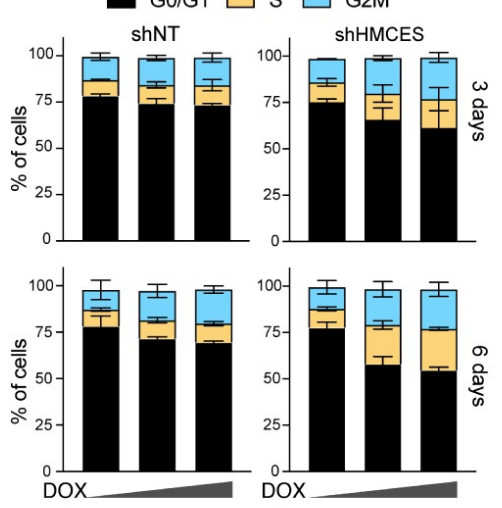

D

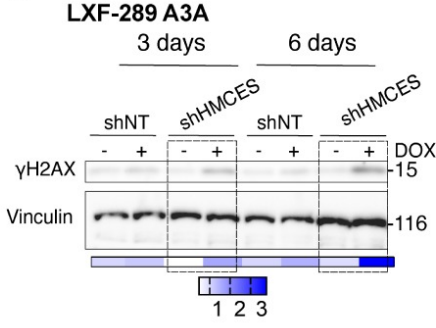

$\mathbf{F}$

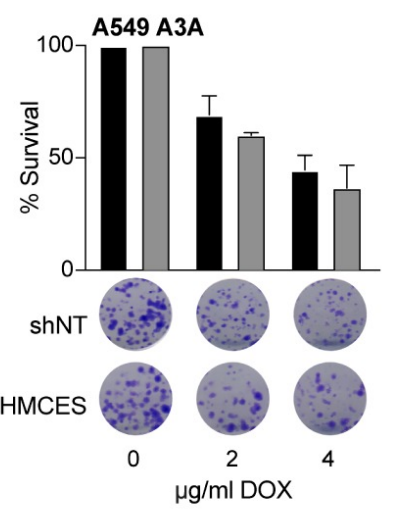

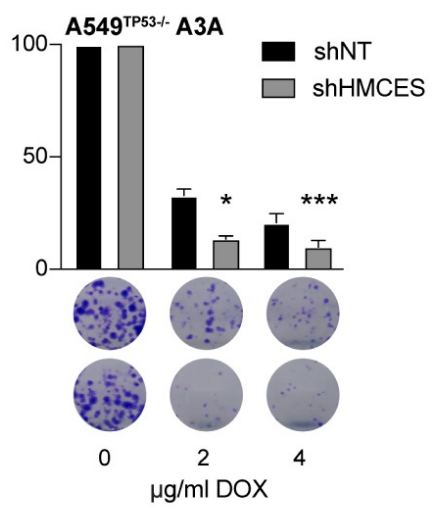

$\mathbf{G}$
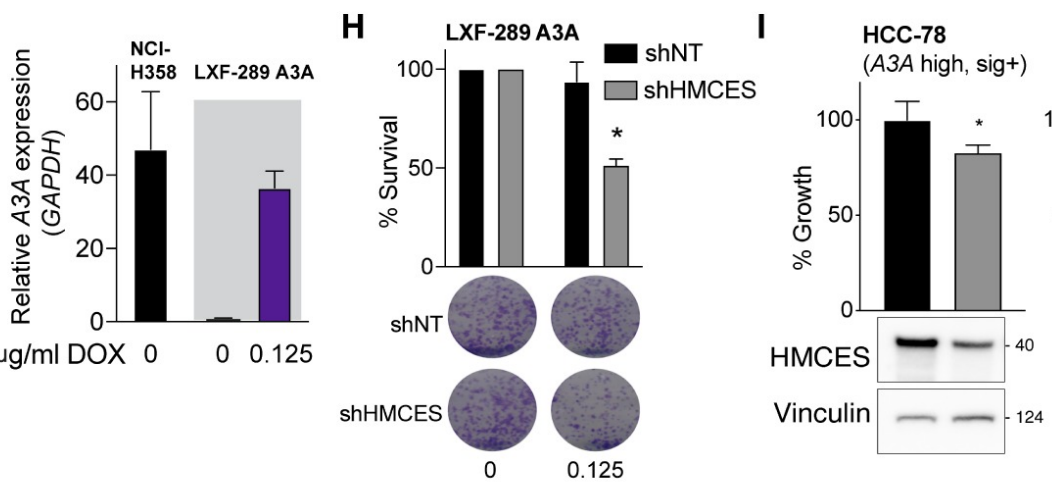

NCI-H2122

(A3A low, sig-)

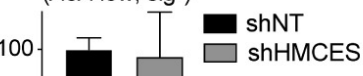


423 Fig 4. Validation of the effects of HMCES depletion in multiple genetic

424 backgrounds. (A) HMCES levels in LXF-289 A3A and NCl-H358 A3A cell lines by

425 qRT-PCR and western blot following transduction with shHMCES or a non-targeting 426 shRNA (shNT). The qRT-PCR validation was repeated at least three times and MW 427 is indicated in kilodaltons. (B) Reduction of HMCES sensitizes LXF-289 A3A cells to 428 A3A expression in a growth assay for 6 and 10 days. (C) Representative histograms 429 of cell cycle progression (left panels) and quantitative analysis of LXF-289 A3A 430 shHMCES and shNT (right panels). Cells were treated with DOX (0, 1 or $2 \mathrm{ug} / \mathrm{ml})$ 431 and harvested after 3 and 6 days. (D) Western blot of H2AX-S139 phosphorylation $432(\gamma \mathrm{H} 2 \mathrm{AX})$ in LXF-289 shHMCES and shNT cells after 3-6 days of A3A expression. 433 Relative phosphorylation (0-3) was calculated normalizing the band densities of $434 \mathrm{yH} 2 \mathrm{AX}$ to total Vinculin signal. $\mathrm{MW}$ is indicated in kilodaltons. (E) Reduction of 435 HMCES sensitizes NCl-H358 A3A cells to A3A expression in a clonogenic survival 436 assay after 15 days. (F) The effect of HMCES depletion is TP53-dependent. 437 Clonogenic survival assays of A549 or A549 ${ }^{\text {TP53-/- }}$ cells are shown 10 days after 438 treatment with the indicated dose of DOX. (G) A3A mRNA expression levels in LXF$439289 \mathrm{~A} 3 \mathrm{~A}$ (0 and $0.125 \mathrm{ug} / \mathrm{ml}$ of doxycycline) and the parental $\mathrm{NCl}-\mathrm{H} 358$ cell line 440 relative to GAPDH measured by qRT-PCR (repeated two times, mean and SEM are 441 shown). (H) Depletion of HMCES sensitizes LXF-289 A3A cells to A3A expression 442 following low levels of DOX treatment in a clonogenic survival assay. (I) Growth 443 inhibition (percentage of growth rate) measured with alamarBlue for HCC-78 (A3A 444 expressing, A3 mutational signature positive) and $\mathrm{NCl}-2122$ (A3A low, A3 mutational 445 signature negative) cell lines transduced with shNT or shHMCES. HMCES levels are 
446 shown, Vinculin is used as a loading control. Statistical analysis of shHMCES versus

447 shNT in all panels was performed using a one-tailed unpaired $t$-test; error bars

448 indicate SD. ${ }^{*}, p \leq 0.05,{ }^{* *}, p \leq 0.01,{ }^{* * *}, p \leq 0.001$. For each time point, growth assays

449 and clonogenic survival assays were repeated 3 times.

451 Sensitivity of A3A expressing cells to HMCES loss is enhanced by DNA 452 damage

453 In addition to sensitizing to A3A, previous data implicated HMCES in the sensitivity 454 to a limited number of DNA damaging agents that included ionizing radiation (IR) 455 and $\mathrm{KBrO}_{3}[42,59]$. Considering this, and that DNA repair factors involved in multiple 456 DSB repair pathways were identified in our A3A screens (Fig 2E), we examined the 457 effects of combinatorial treatments on A3A-mediated toxicity. Survival of LXF-289 458 A3A cells was analyzed with or without DOX in combination with $\mathrm{IR}$ or $\mathrm{KBrO}_{3}$ 459 treatment. Both agents showed increased toxicity in cells expressing A3A (Fig 5A; $460 \quad p \leq 0.05$ for synergistic activity, by t-test against a Bliss independence baseline)[64]. 461 We next examined the relative importance of the three PI3K-like kinases (PIKKs), 462 ATM, ATR and DNA-PKcs, that regulate many of the individual proteins identified in 463 the screens. LXF-289 cells were treated with DOX to induce A3A and each of the 464 PIKKs was inhibited using small molecule inhibitors[65]. As previously reported, we 465 saw that the toxicity of A3A overexpression was strongly enhanced following 466 treatment with ATR inhibitors[32,33]. In addition, we saw that inhibitors of ATM and 467 DNA-PKcs, that play a key role in DSB repair, led to synergistic cell killing with A3A 468 overexpression ( $p \leq 0.05$ ) albeit to a more modest extent than with the ATR inhibitor 469 or with IR (Fig 5A). 
471 We next examined the influence of HMCES on combination treatments by

472 generating knockout cell lines (HMCES KO) in the LXF-289 A3A background using

473 CRISPR/Cas9 and single cell isolation (Fig 5B). Five clones with no detectable

474 HMCES protein levels (Fig 5B; bold type) were pooled to generate an HMCES KO

475 cell culture for subsequent analysis. HMCES KO impaired the colony-forming

476 capacity of LXF-289 A3A cells, and this was further reduced upon expression of A3A

477 following DOX treatment (Fig 5C). HMCES KO cells also showed hypersensitivity to

478 the inhibition of any of the PIKKs, in the absence of exogenous DNA damaging

479 agents, as well as to treatment with IR or $\mathrm{KBRO}_{3}$ (Fig 5D). Together, our data point

480 to HMCES as an important dependency of cancer cells for survival and suggest that

481 this can be exploited using combination therapies.

A
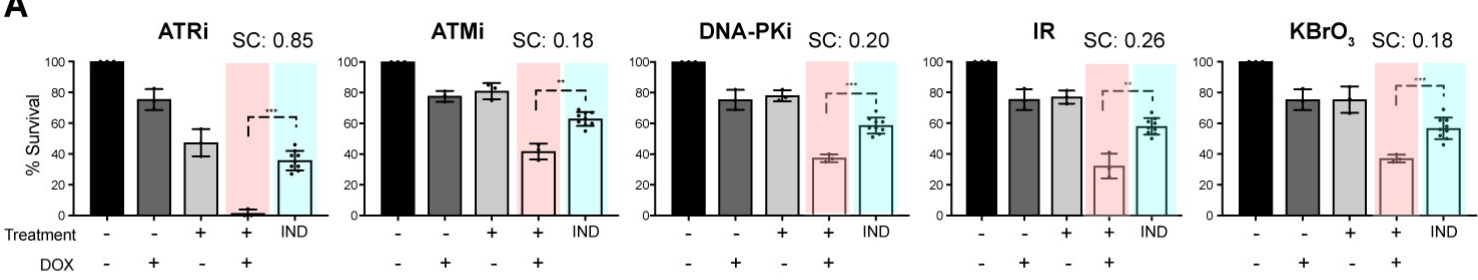

B

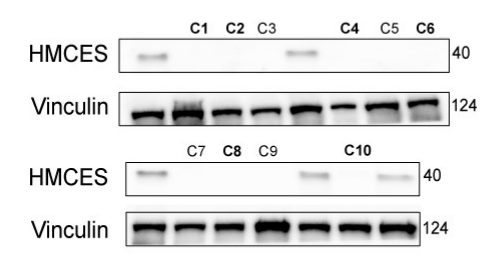

D
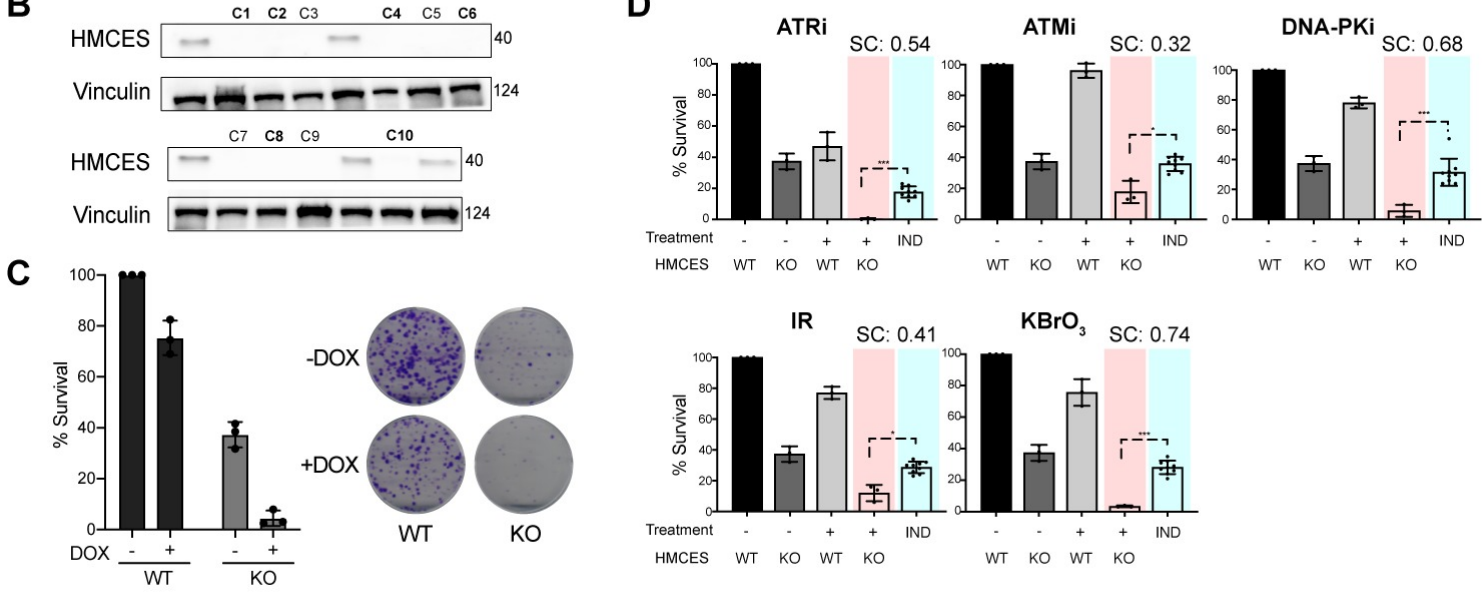

482 
483 Fig 5. A3A expression sensitizes to DNA damage and HMCES loss. (A)

484 Clonogenic survival measured by the colony formation assay in LXF-289 A3A cells

485 after exposure to the indicated small molecule inhibitor, IR (5 Gy), or treatment with

$4860.1 \mathrm{mM} \mathrm{KBrO}_{3}$ with or without $\mathrm{DOX}(0.125 \mathrm{ug} / \mathrm{ml})$ to induce $A 3 A$ expression. (B)

487 HMCES western blot of lysates from HMCES WT and KO LXF-289 A3A clones.

488 Vinculin was used as a protein loading control and MW is indicated in kilodaltons.

489 (C) Clonogenic survival assay of LXF-289 HMCES WT and KO cells upon over-

490 expression of A3A by DOX. (D) Clonogenic survival assay comparing HMCES WT

491 and $\mathrm{KO}$ cells after treatment with the indicated small molecule inhibitor, exposure to

492 IR (5 Gy), or treatment with $0.1 \mathrm{mM} \mathrm{KBrO}_{3}$ with or without DOX to induce A3A

493 expression. For panels A and D, the "IND" column shows a Bliss independence

494 model of additive activity of the two treatments, against which the combined

495 treatment is tested (using $t$-test, two-tailed) to estimate synergistic activity[64]. SC,

synergy score. ${ }^{*}, p \leq 0.1,{ }^{* *}, p \leq 0.05^{* * *}, p \leq 0.01$. Each experiment was repeated

497 two times.

498

Screening HMCES deficient cells reveals additional modifiers of the A3A

response

501 As HMCES KO cells could still tolerate some A3A expression, we performed a

502 secondary CRISPR/Cas9 genome-wide screen to identify mediators of survival that

503 were specific for LXF-289 A3A HMCES KO cells (Fig 6A). Positively selected genes

504 in this assay are those whose deletion lessens the fitness penalty due to loss of

505 HMCES upon A3A overexpression (alleviating epistasis), while negatively selected

506 genes are those whose deletion increases this fitness penalty (aggravating 
507 epistasis). Expectedly, this screen identified a strong positive selection for the loss

508 of $A 3 A$, presumably by targeting our inducible gene. Further, it identified UNG, the

509 gene encoding the primary uracil-DNA glycosylases UNG1 and UNG2, that localize

510 to the mitochondria and nucleus, respectively. This indicated that preventing the

511 generation of AP-sites by A3A conferred survival to HMCES KO cells, consistent

512 with previous work[22,49]. In addition, the loss of multiple genes encoding subunits

513 of the Mediator complex (CCNC, MED24, MED25 and MED16), splicing regulators

514 (SCAF1, SCAF8), the FBXW7 E3 Ubiquitin ligase (a common tumor suppressor

515 gene), the mismatch repair protein MSH2, the Protein phosphatase 4 subunit

516 SMEK1 (PPP4R3A) that dephosphorylates $\gamma \mathrm{H} 2 \mathrm{AX}$ [66], the ATF2 transcription factor

517 and FADD (FAS-associated death domain protein), were among high scoring hits

518 that were positively selected in HMCES KO cells (S6 Table).

520 Among negatively selected genes in HMCES KO cells, TDP1 (tyrosyl-DNA

521 phosphodiesterase 1) was one of few genes implicated in DNA repair. TDP1 can

522 resolve 3'-AP-sites and is essential in cells lacking APE1, which promotes the repair

523 of AP-sites by BER[67-69]. VCPIP1 was also a strong hit implicated in DNA repair.

524 VCPIP1 is a deubiquitinase that is activated by ATM/ATR and involved in the

525 removal of protein-DNA crosslinks through the regulation of SPRTN, that is critical

526 for damage prevention during DNA replication[70,71]. In addition, the gene encoding

527 the Protein phosphatase 2A subunit (PPP2R2A) was negatively selected. PPP2R2A

528 is a negative regulator of ATM-CHK2 and a candidate tumor suppressor gene 529 commonly deleted in ovarian, prostate, liver and bladder cancers[72-74]. 
bioRxiv preprint doi: https://doi. org/10.1101/2021.02 05.429803: this version posted February 6, 2021. The copyright holder for this preprint

(which was not certified by peer review) is the author/funder, who has granted bioRxiv a license to display the preprint in perpetuity. It is made available under aCC-BY-NC 4.0 International license.

531 Together, these data indicate that the sensitivity of HMCES null cells can be

532 mitigated by the loss of UNG, implicating AP-site generation in the toxicity, and that

533 TDP1, and potentially VCPIP1/SPRTN, likely represent key backup activities for the

534 resolution of APOBEC3A-mediated damage to promote cell survival.

535

536

537

538

539 
A

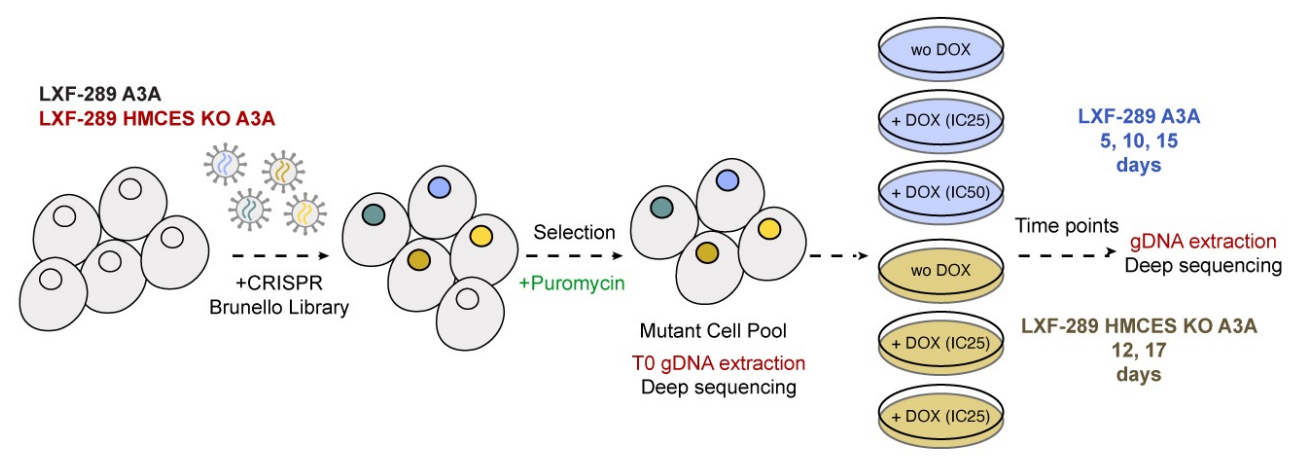

B

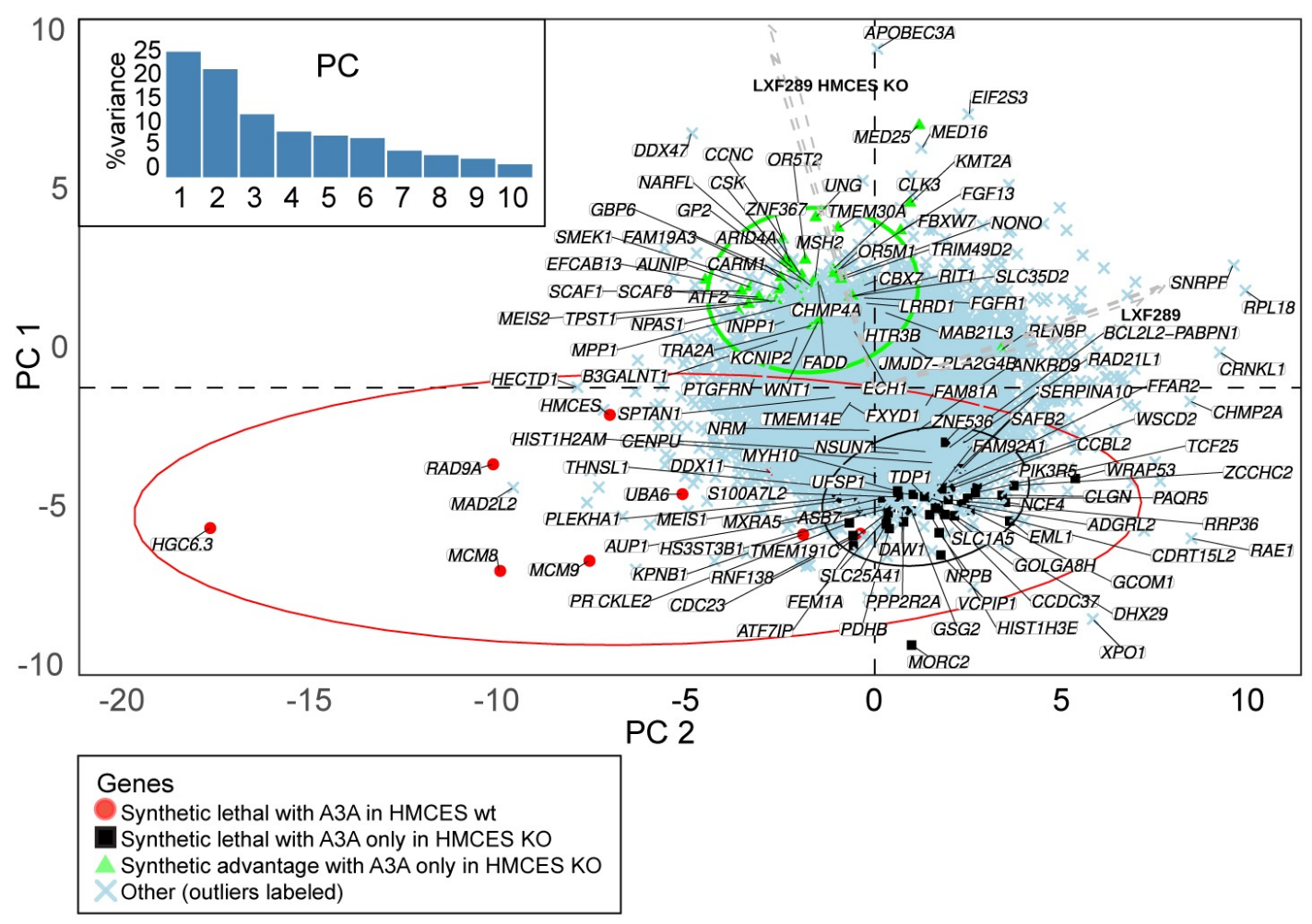

541 Fig 6: Secondary screening identifies modifiers of the response to A3A in

542 HMCES KO LXF-289 cells. (A) Schematic of the secondary screen in HMCES KO

543 LXF-289 cells. (B) PC analysis of A3A-conditional LFC scores for all genes across

544 all 10 experimental conditions (see labels next to arrows, which show loadings of the

545 conditions on PC1 and PC2; HMCES wt refers to the parental LXF-289 cell line. Top

546 genes, prioritized by score are highlighted on the figure for each indicated 
547 comparison: green, alleviating epistasis; black, aggravating epistasis; red synthetic

548 lethal in HMCES wt. Gene level scores and GO analysis are included in S6 Table

549 and S7 Table and additional epistasis analysis is included in S11 Fig.

\section{Discussion}

552 Our results establish that HMCES is a key mediator of A3A toxicity in cancer cells.

553 Given the increased levels of $\gamma \mathrm{H} 2 \mathrm{AX}$ DNA damage signaling observed in HMCES

554 knockdown cells, as well as the enrichment in DSB repair factors in our screens, our

555 results suggest that DSBs may be a major driver of A3A toxicity. Notably absent in

556 our primary screens were factors involved in the BER pathway that would normally

557 resolve AP-sites and promote the base changes that are evident in the APOBEC

558 mutational signature. We interpret this to mean that A3A lesions are likely not toxic

559 outside of S-phase, where they can be repaired by BER and likely additional

560 pathways.

562 This proposition is consistent with recently published work demonstrating that

563 HMCES depletion sensitizes both immortalized human cells and cancer cells to A3A

564 expression[49]. In addition, the study showed that HMCES loss reduced replication

565 fork elongation in a manner dependent on the UNG-mediated production of AP-sites,

566 using a uracil-DNA glycosylase inhibitor. UNG2 depletion was also previously shown

567 to suppress the accumulation of replication fork associated AP-sites and DSBs in

568 ATRi treated A3A-expressing cells[33]. Curiously, UNG2 depletion caused lethality

569 in A3B-expressing cells through a mechanism dependent on MMR and TP53[75].

570 We did not identify any glycosylases as sensitizers or suppressors of A3A-mediated 
571 toxicity in our primary screens, regardless of TP53 status. However, our secondary

572 screen in HMCES KO cell lines identified UNG as a major positively selected hit in

573 cells expressing A3A, reinforcing the proposition that AP-site production underlies

574 the sensitivity of cells to A3A expression[42,49]. It also suggests a mechanistic

575 divergence between the toxicity of $A 3 A$ and $A 3 B$ expression. In addition, our

576 secondary screens identified the mismatch repair protein MSH2 as positively

577 selected, consistent with our recent data suggesting that APOBEC3A-mediated

578 mutagenesis is mediated by MMR activity, resulting in the characteristic omikli

579 pattern of clustered mutations[7]. In contrast, UNG, MSH2 or other MMR proteins,

580 were not identified as strong influencers of the survival of HMCES KO cells in the

581 absence of A3A or DNA damage in our screens, or in recent screens performed by

582 others in HMCES KO cells in a HEK293 background[76].

584 Replication fork slowing following A3A expression was shown to be due in part to

585 the recruitment of TLS polymerases, particularly POL $\zeta$, as well as increased

586 accessibility to APE1 endonuclease activity that is likely the source of DSBs[49].

587 While we did not identify APE1, potentially due to redundancy with other activities,

588 we did find the POL $\zeta$ subunit MAD2L2 as an A3A sensitizer (Figs 2C-2E). Notably,

589 this was specific to the LXF-289 cancer cell line, suggesting that the genetic

590 background may have an appreciable impact on replication fork protection and

591 stability and how cells respond to AP-sites at replication forks.

593 Aside from HMCES, the overall agreement between cell lines at the individual gene 594 level was limited in our A3A screens. A previous analysis of essential genes using a 
595 DNA repair library in HEK293 HMCES KO cells identified numerous proteins

596 involved in HR and TLS, suggesting that loss of HMCES was synthetically lethal with

597 the attenuation of these repair pathways[76]. In the absence of A3A expression, we

598 observed very limited overlap with that study when compared to our data in LXF-289

599 HMCES KO cells, with the ribonucleotide reductase subunit RRM1, clamp loader

600 subunit RFC3 and HR factor XRCC3 being the only notable overlapping hits among

601 negatively selected genes. Together, this further highlights that the individual genetic

602 or epigenetic status of particular cell lines may play a significant role in the response

603 to A3A expression, as well as to HMCES loss. This is supported by the fact that A3A

604 expression caused variable levels of cell cycle arrest that was cell line dependent

605 (Fig 1). This may reflect the status of individual DNA repair pathways or DNA 606 replication fork rates in the different genetic backgrounds. Despite the different 607 phenotypic outcomes between cell lines, HMCES emerged as a common and 608 prominent hit between the cell lines screened in our work (using an experimental

609 system for A3A overexpression), as well as many other cell lines examined in the 610 Project Achilles screens (using observational analysis of A3A mutational signatures 611 in the cell line exomes)[77].

613 TP53 status clearly has a major influence on the genetic interaction between 614 HMCES loss and A3A expression, implicating G1/S checkpoint status in the 615 tolerance of A3A expression. TP53 status was shown to have a major influence on 616 CRISPR/Cas9 survival screens and it is intuitive that checkpoint status would limit 617 toxic DNA damage generated during S-phase and prevent mitotic catastrophe 618 resulting from under-replicated DNA entering mitosis[78]. As A3A-mediated damage 
619 of ssDNA is S-phase specific, our results would again be consistent with the recently

620 proposed model that HMCES shields AP-sites in ssDNA from processing by BER

621 endonucleases that would generate AP-sites and toxic DSBs, or from replication by

622 TLS polymerases that would result in increased mutagenesis[27,42,43,49,76]. As

623 the enzymatic activities of HMCES have been implicated in this function,

624 accumulating data suggests that targeting HMCES would be an attractive strategy

625 for the specific sensitization of A3A-expressing, TP53-deficient cancers.

627 Inhibition of the ATR-CHK1 kinases, that activate cell cycle checkpoints in S and G2

628 in response to replication stress, was shown to enhance A3A-mediated toxicity in 629 AML, lung, ovarian and osteosarcoma cell lines[32,33]. Our results further extend 630 the robustness of this observation to additional lung cancer cell lines. In contrast to 631 previous work, we also found increased sensitivity to ATM and DNA-PKcs inhibitors 632 in LXF-289 NSCLCs lacking HMCES, potentially reflecting differences in the genetic 633 backgrounds analyzed[75]. As inhibitors for the PIKKs are in multiple clinical trials, 634 targeting HMCES may represent a strategy to enhance their efficacy, particularly in 635 combination with radiotherapy. This may be particularly potent in cancers with 636 PPP2R2A deletions[74]. Loss of PPP2R2A enhanced toxicity of A3A in HMCES KO 637 cells, and depletion or PPP2R2A was shown to enhance the toxicity of ATR-CHK1 638 inhibitors in NSCLC[79]. Our finding that TDP1 was the primary DNA repair protein 639 negatively selected specifically in HMCES KO cells expressing A3A indicate that 640 TDP1 inhibitors could be also used in conjunction with HMCES depletion/inhibition 641 to sensitize APOBEC3-expressing cancer cells. Numerous TDP1 inhibitors are 
642 currently being explored in clinical trials to sensitize cells to topoisomerase 643 inhibitors[80].

645 In addition to sensitizing to A3A-expression, HMCES deficiency also sensitized cells

646 to treatment with IR and $\mathrm{KBrO}_{3}$ treatment (Figs 3 and 5)[42,59]. As previously

647 discussed, HMCES depletion sensitizes to a very limited spectrum of damaging

648 agents compared to other hits in our screen that play more general roles in damage

649 tolerance. The observation that additional hits, namely the poorly characterized

650 SAGA complex component ATXN7L3 and ubiquitin-activating enzyme UBA6,

651 shared overlapping profiles of DNA damage sensitivity as HMCES, suggests that a

652 more definitive characterization of their roles is warranted in future work.

654 Collectively, existing data suggests that inhibition of HMCES is a promising strategy

655 to suppress the APOBEC overexpressing, hypermutating tumor cell population,

656 thereby slowing down the accumulation of genetic heterogeneity and preventing 657 acquisition of new driver mutations or drug resistance mutations. Moreover, HMCES

658 inhibition could augment the use of radiotherapy, which is widely used in the 659 treatment of many cancer types and enhance the effectiveness of small molecule 660 inhibitors for DNA damage signaling kinases and repair enzymes that are currently 661 being developed and tested in clinical trials.

662

663

664 


\section{Methods}

666 Cell culture and generation of doxycycline-induced lung adenocarcinoma 667 (LUAD) cell lines

669 the American Type Culture Collection (ATCC) and the Deutsche Sammlung von

670 Mikroorganismen und Zellkulturen GmbH (DSMZ) and maintained with RPMI-1640

671 or DMEM medium and supplemented with $10 \%$ fetal bovine serum and $5 \%$ penicillin-

672 streptomycin. The doxycycline-inducible HA-tagged A3A plasmid (pSLIK-Neo A3A)

673 was a kind gift from the Weitzman lab[27]. Lentiviral particles were generated by 674 transfection of HEK-293T cells. After transduction with the pSLIK-A3A lentivirus, 675 LUAD cells were selected in $1 \mathrm{mg} / \mathrm{mL}$ Geneticin (Ibian Technologies).

\section{Growth arrest and colony formation assays}

677 For growth assays, cells were plated at density of 1,000 cells/well in a 96 well plate.

678 After $24 \mathrm{hrs}$, cells were treated with increasing doses of doxycycline $(0-8 \mathrm{ug} / \mathrm{ml})$ and 679 cultured for $72 \mathrm{hrs}$. AlamarBlue reagent (ThermoFisher Scientific) was added to cell 680 culture media $4 \mathrm{hrs}$ prior to reading fluorescence with a SYNERGY H1M 681 fluorescence plate reader. For the colony formation assays, between $250-1000$ cells 682 per well were plated in a 12 well plate. Colonies were fixed with formalin (Sigma) 683 and stained with a $0.01 \%$ crystal violet (Sigma) solution in $20 \%$ methanol. For some 684 cell lines, quantification was performed by reading absorbance at $590 \mathrm{~nm}$ after the 685 addition of $10 \%$ acetic acid. 


\section{Drug sensitivity assays}

687 Colony-forming assays for drug sensitivity testing were performed by plating the cells

688 at a density of 500 cells/well in a 6 well-plate, in triplicate. $24 \mathrm{hrs}$ after plating, the

689 following drug treatments were used: DNA-PKi (KU57788) 1uM

690 (MedChemExpress), ATMi (KU55933) 5uM (Sigma), ATRi (AZD6738) 0.5uM

691 (MedChemExpress), $\mathrm{KBrO}_{3} 0.1 \mathrm{mM}$ (Sigma). IR (5 Gy) was administered using a

692 Maxishot.200 X-Ray cabinet (Krautkramer Forster). For the induction of A3A

693 expression, doxycycline was added at a concentration of $0.125 \mathrm{ug} / \mathrm{ml}\left(\mathrm{IC}_{25}\right)$. The

694 drug treatment was maintained in the growth media for the duration of the 695 experiment (10 days), after which cells were fixed and stained with crystal violet. The 696 number of colonies was quantified with Fiji (ImageJ). Colony-forming capacity is 697 presented as a percentage of the vehicle-treated (DMSO $0.025 \%$ ) control.

698 Cell cycle analysis

699 Cells were fixed in $70 \%$ ethanol for at least $2 \mathrm{hrs}$ at $-20^{\circ} \mathrm{C}$ and resuspended in a PBS 700 solution containing $35 \mathrm{ug} / \mathrm{ml}$ propidium iodide (Sigma) and $100 \mathrm{ug} / \mathrm{ml}$ RNAse A 701 (Roche). Between 5000-10000 cells were analyzed per sample. Data was acquired 702 on a Gallios A94303 Flow Cytometer (Beckman Coulter) in the Cytometry core 703 facility of the University of Barcelona and analyzed by FlowJo software.

704 RNA extraction, cDNA synthesis and qRT-PCR

705 RNA extraction was performed using the Maxwell 16 LEV simplyRNA cell Kit 706 (Promega) according to manufacturer's instructions. cDNA synthesis was performed 
707 with the high-capacity cDNA reverse transcription kit (Life Technologies).

708 Quantitative PCR (qRT-PCR) was performed with SYBR Select Master Mix for CFX

709 (Applied Biosystems) or TaqMan universal PCR Master Mix II (Applied Biosystems)

710 on a StepOnePlus Real-time PCR System (Applied Biosystems). Probes and

711 primers are shown at S8 Table.

\section{Generation of stable KO and knockdown cells}

713 For A549 \pm A3A and LXF-289 \pm A3A cell lines, the NickaseNinja (ATUM) vector co-

714 expressing two gRNAs (pD1401-AD: CMV-Cas9N-2A-GFP, Cas9-ElecD) was used

715 to generate the TP53 KO and the HMCES KO cells. TP53 gRNA sequences

716 (GCAGTCACAGCACATGACGG) (GATGGCCATGGCGCGGACGC) and HMCES

717 gRNA sequences

(CAGTGAATGGATCTCTACAA)

718 (GAGCTTGCGCCTACCAGGAT) were designed using the ATUM gRNA Design

719 Tool. 48 hrs post-transduction, positive GFP cells were sorted by FACS (BD

720 FACSAriaTM Fusion) and plated into 96-well plates. After 15 days, clones were

721 collected and validated by western blot using the following primary antibodies: p53

722 (sc-47698, Santa Cruz); vinculin (V9264, Sigma); HMCES (HPA044968, Atlas

723 Antibodies). The HMCES knockdown stable cell lines (HCC-78, NCl-H2122, LXF-

724289 A3A, NCl-H358 A3A, A549 A3A, and A549TP53-/ A3A) were made using the

725 Mission shRNA lentiviral vector NM_020187.1-133s1c1 (Sigma). Lentiviral particles

726 were produced in HEK293T cells using a pLKO.1-shRNA plasmid. The cell lines

727 were transduced and selected with puromycin for $72 \mathrm{hrs}$. As a control, we transduced

728 LXF-289 (A3A) cells with the non-mammalian shRNA Control Plasmid DNA shC002

729 (Sigma). 


\section{CRISPR/Cas9 screening}

731 For sgRNA screening of the A549 $\pm A 3 A, A 549^{\text {TP53-- }} \pm A 3 A, L X F-289 \pm A 3 A$, cells

732 were infected with the Brunello CRISPR Knockout Pooled Library (73179-LV, 733 Addgene). Infection with lentiviruses was performed at a MOI $\leq 0.4$ for all cell lines.

734 At 24 hrs post-infection, the medium was replaced with a selection medium 735 containing puromycin $(2 \mathrm{ug} / \mathrm{mL})$. After 5-6 days of selection, cells were split into the 736 different experimental conditions: For LXF-289 cell line, without and with doxycycline

737 ( 0.125 and $2 \mathrm{ug} / \mathrm{ml}$ corresponding to $\mathrm{IC}_{25}$ and $\mathrm{IC}_{50}$ respectively). For LXF-289 738 HMCES KO secondary screening, without and with doxycycline $(0.03$ and 0,125 $739 \mathrm{ug} / \mathrm{ml}$ corresponding to $\mathrm{IC}_{25}$ and $\mathrm{IC}_{50}$ respectively). For $\mathrm{A} 549$ cell line, without and 740 with doxycycline $(3.9 \mathrm{ug} / \mathrm{ml}$ ). All cell lines were passaged every 3 days (up to 15 741 days) and for each time point, the number of cells needed to maintain the 742 predetermined coverage of $400-500$ fold was taken. DNA extraction was performed 743 using the DNA genomic Kit (Puregene Cell and Tissue Kit).

744 NGS Library Preparation and sequencing

745 NGS libraries were prepared by two-step PCR, for the first one a total of 20 ug of 746 DNA per a $12 \mathrm{X}$ reaction was used, for the second PCR a set of primers harboring 747 Illumina TruSeq adapters as well as the barcodes for multiplexing were used (for all 748 primers used see S8 Table). Sequencing was carried out in the CNAG sequencing 749 unit using 6 lanes of a $1 \times 50$ HiSeq.

750 Statistics 
751 The statistical analyses were performed using Prism software version 8.0. Each

752 functional experiment was repeated two times or three times (as specified in the

753 figure or legend). Differences between groups were analyzed by the Student t-test

754 assuming unequal variances.

755 Independent validation

756 We downloaded mutational signatures for the cell lines from Petljak et al[63] and 757 gene essentiality fitness score from Project Achilles[57]. We selected the cell lines

758 from HNSC, LUAD and LUSC. For the top 10 scoring genes in our analysis, we fitted

759 a linear regression model between the cell lines fitness score and the signature

760 loadings for signatures SBS2, SBS13 and SBS2+SBS13 (APOBEC signatures). We

761 compared the slope and p-values obtained. The p-value is obtained from a t-test

762 (one-tailed lower).

763 In silico analysis of DNA damage sensitivity to DNA damaging agents

764 We downloaded the previously published data for the z-scores after genotoxin 765 exposure screens[59]. We compared how our top 50 genes (essential upon A3A 766 overexpression) versus 50 genes that are not essential in our screens behaved after

767 the genotoxin exposure.

768 In silico analysis of CRISPR/Cas9 screening results

769 For alignment of the generated reads to the library, read counting, read count 770 normalization, quality control (QC) analysis of the samples, and calculation of the 771 sgRNA counts log2 fold change, we used MAGeCK-VISPR[51]. For pair wise 
772 comparisons, we employed the robust rank aggregation (RRA) algorithm, using as

773 treatment the DOX-induced A3A sample, for each cell line (A549, A549 ${ }^{\text {TP53-/- }}$, and

774 LXF-289) and time point.

775

776 Estimation of gene essentiality and sgRNA efficiency was achieved using the

777 maximum-likelihood estimation (MLE) algorithm provided by MAGeCK-VISPR.

778 Namely, gene essentiality was estimated by comparison of the normalized sgRNA

779 counts between each sample (A549 and A549 ${ }^{\text {TP53-I- }}$ time 9, 12, and 15, and LXF-289

780 time 5, 10, and 15) and its corresponding time 0 sample, which yielded a beta score

781 per gene and sample. The beta score distribution for each sample was standardized

782 by subtraction of the mean and division by the standard deviation (SD), and a final

783 gene essentiality score was obtained by averaging the resulting Z-scores across

784 samples.

785

786 Finally, we used the FluteMLE function from the R package "MAGeCKFlute"[81] for

787 i) normalization of the beta scores yielded by MAGeCK-VISPR MLE using a built-in

788 set of 622 essential genes as a reference, and ii) comparison of the essentialities

789 between conditions (DOX-induced A3A vs. control) within each cell line and time

790 point, applying a significance cutoff of two SD (S4 Fig). This allowed us to identify

791 genes that were negatively selected in the A3A-expressing samples, but not selected

792 in the control samples.

793

794 Data Availability Statement 
795 All data is included as Supplementary material or is available upon request. Analyses

796 that used data from Olivieri et al. [59] are available at Mendeley data:

797 https://data.mendeley.com/datasets/gfcn2wmrpf/1.

798

799 Acknowledgements

800 We thank members of the Stracker and Supek labs for input and discussions, M.

801 Weitzman and A. Green for sharing reagents and unpublished data.

802 Funding

803 J.B., M.M. and F.S. were supported by the ERC Starting Grant (757700 "HYPER-

804 INSIGHT", to F.S). I.G.C. was funded by an AECC fellowship. M.M.A. and J.E.C.

805 were supported by the Spanish Ministry of Science, Innovation and Universities

806 (BFU2017-89833-P "RegioMut", to F.S.). T.H.S. was funded by the Spanish Ministry

807 of Science, Innovation and Universities (MCIU: PGC2018-095616-B-I00/GINDATA

808 and FEDER) and the Intramural Research Program of the National Institutes of

809 Health, National Cancer Institute. The T.H.S. and F.S. labs are supported by the

810 Centres of Excellence Severo Ochoa award and the CERCA Programme. F.S. is

811 funded by the ICREA Research Professor programme. The funders had no role in

812 study design, data collection and analysis, decision to publish, or preparation of the

813 manuscript.

\section{Author contributions}

815 J.B. performed the majority of the experiments, designed experiments, analyzed

816 data and edited the manuscript, I.G.C. performed experiments and analyzed data, 
817 M.M.A., M.S. and J.E.C. performed computational analyses, M.M performed

818 experiments, T.H.S. and F.S. supervised the project, designed experiments,

819 analyzed data, and wrote and edited the manuscript.

820

821 Competing interests statement:

822 The authors declare no competing interests

823 


\section{References}

1. Nik-Zainal S, Alexandrov LB, Wedge DC, Van Loo P, Greenman CD, Raine $\mathrm{K}$, et al. Mutational processes molding the genomes of 21 breast cancers. Cell. 2012;149: 979-993. doi:10.1016/j.cell.2012.04.024

2. Nik-Zainal S, Wedge DC, Alexandrov LB, Petljak M, Butler AP, Bolli N, et al. Association of a germline copy number polymorphism of APOBEC3A and APOBEC3B with burden of putative APOBEC-dependent mutations in breast cancer. Nat Genet. 2014;46: 487-491. doi:10.1038/ng.2955

3. Burns MB, Temiz NA, Harris RS. Evidence for APOBEC3B mutagenesis in multiple human cancers. Nat Genet. 2013;45: 977-983. doi:10.1038/ng.2701

4. Roberts SA, Lawrence MS, Klimczak LJ, Grimm SA, Fargo D, Stojanov P, et al. An APOBEC cytidine deaminase mutagenesis pattern is widespread in human cancers. Nat Genet. 2013;45: 970-976. doi:10.1038/ng.2702

5. Roberts SA, Sterling J, Thompson C, Harris S, Mav D, Shah R, et al. Clustered mutations in yeast and in human cancers can arise from damaged long single-strand DNA regions. Mol Cell. 2012;46: 424-435. doi:10.1016/j.molcel.2012.03.030

6. Chen J, Miller BF, Furano AV. Repair of naturally occurring mismatches can induce mutations in flanking DNA. Elife. 2014;3: e02001. doi:10.7554/eLife.02001

7. Mas-Ponte D, Supek F. DNA mismatch repair promotes APOBEC3-mediated diffuse hypermutation in human cancers. Nat Genet. 2020;52: 958-968. doi:10.1038/s41588-020-0674-6

8. Henderson S, Chakravarthy A, Su X, Boshoff C, Fenton TR. APOBECmediated cytosine deamination links PIK3CA helical domain mutations to human papillomavirus-driven tumor development. Cell Rep. 2014;7: 18331841. doi:10.1016/j.celrep.2014.05.012

9. McGranahan N, Favero F, de Bruin EC, Birkbak NJ, Szallasi Z, Swanton C. Clonal status of actionable driver events and the timing of mutational processes in cancer evolution. Sci Transl Med. 2015;7: 283 ra54. doi:10.1126/scitransImed.aaa1408

10. Cannataro VL, Gaffney SG, Sasaki T, Issaeva N, Grewal NKS, Grandis JR, et al. APOBEC-induced mutations and their cancer effect size in head and neck squamous cell carcinoma. Oncogene. 2019;38: 3475-3487. doi:10.1038/s41388-018-0657-6

11. Alexandrov LB, Nik-Zainal S, Wedge DC, Aparicio SAJR, Behjati S, Biankin $\mathrm{AV}$, et al. Signatures of mutational processes in human cancer. Nature. 2013;500: 415-421. doi:10.1038/nature12477

12. Lada AG, Dhar A, Boissy RJ, Hirano M, Rubel AA, Rogozin IB, et al. AID/APOBEC cytosine deaminase induces genome-wide kataegis. Biol Direct. 2012;7: 47; discussion 47. doi:10.1186/1745-6150-7-47

13. Taylor BJ, Nik-Zainal S, Wu YL, Stebbings LA, Raine K, Campbell PJ, et al. DNA deaminases induce break-associated mutation showers with implication of APOBEC3B and 3A in breast cancer kataegis. Elife. 2013;2: e00534. doi:10.7554/eLife.00534 
870

871

872

873

874

875

876

877

878

879

880

881

882

883

884

885

886

887

888

889

890

891

892

893

894

895

896

897

898

899

900

901

902

903

904

905

906

907

908

909

910

911

912

913

914

915

916

14. Franco I, Helgadottir HT, Moggio A, Larsson M, Vrtačnik $P$, Johansson A, et al. Whole genome DNA sequencing provides an atlas of somatic mutagenesis in healthy human cells and identifies a tumor-prone cell type. Genome Biol. 2019;20: 285. doi:10.1186/s13059-019-1892-z

15. Ullah I, Karthik G-M, Alkodsi A, Kjällquist U, Stålhammar G, Lövrot J, et al. Evolutionary history of metastatic breast cancer reveals minimal seeding from axillary lymph nodes. J Clin Invest. 2018;128: 1355-1370. doi:10.1172/JCI96149

16. Akre MK, Starrett GJ, Quist JS, Temiz NA, Carpenter MA, Tutt ANJ, et al. Mutation Processes in 293-Based Clones Overexpressing the DNA Cytosine Deaminase APOBEC3B. PLoS One. 2016;11: e0155391.

doi:10.1371/journal.pone.0155391

17. Nikkilä J, Kumar R, Campbell J, Brandsma I, Pemberton HN, Wallberg F, et al. Elevated APOBEC3B expression drives a kataegic-like mutation signature and replication stress-related therapeutic vulnerabilities in p53-defective cells. Br J Cancer. 2017;117: 113-123. doi:10.1038/bjc.2017.133

18. Chan K, Roberts SA, Klimczak LJ, Sterling JF, Saini N, Malc EP, et al. An APOBEC3A hypermutation signature is distinguishable from the signature of background mutagenesis by APOBEC3B in human cancers. Nat Genet. 2015;47: 1067-1072. doi:10.1038/ng.3378

19. Supek F, Lehner B. Clustered Mutation Signatures Reveal that Error-Prone DNA Repair Targets Mutations to Active Genes. Cell. 2017;170: 534547.e23. doi:10.1016/j.cell.2017.07.003

20. Cortez LM, Brown AL, Dennis MA, Collins CD, Brown AJ, Mitchell D, et al. APOBEC $3 A$ is a prominent cytidine deaminase in breast cancer. PLoS Genet. 2019;15: e1008545. doi:10.1371/journal.pgen.1008545

21. Law EK, Levin-Klein R, Jarvis MC, Kim H, Argyris PP, Carpenter MA, et al. APOBEC3A catalyzes mutation and drives carcinogenesis in vivo. J Exp Med. 2020;217. doi:10.1084/jem.20200261

22. Landry S, Narvaiza I, Linfesty DC, Weitzman MD. APOBEC3A can activate the DNA damage response and cause cell-cycle arrest. EMBO Rep. 2011;12: 444-450. doi:10.1038/embor.2011.46

23. Kavli B, Otterlei M, Slupphaug G, Krokan HE. Uracil in DNA--general mutagen, but normal intermediate in acquired immunity. DNA Repair (Amst). 2007;6: 505-516. doi:10.1016/j.dnarep.2006.10.014

24. Sale JE. Translesion DNA synthesis and mutagenesis in eukaryotes. Cold Spring Harb Perspect Biol. 2013;5: a012708. doi:10.1101/cshperspect.a012708

25. Marians KJ. Lesion bypass and the reactivation of stalled replication forks. Annu Rev Biochem. 2018;87: 217-238. doi:10.1146/annurev-biochem062917-011921

26. Kidane D, Murphy DL, Sweasy JB. Accumulation of abasic sites induces genomic instability in normal human gastric epithelial cells during Helicobacter pylori infection. Oncogenesis. 2014;3: e128. doi:10.1038/oncsis.2014.42

27. Green AM, Landry S, Budagyan K, Avgousti DC, Shalhout S, Bhagwat AS, et al. APOBEC3A damages the cellular genome during DNA replication. Cell 
Cycle. 2016;15: 998-1008. doi:10.1080/15384101.2016.1152426

28. Sakofsky CJ, Roberts SA, Malc E, Mieczkowski PA, Resnick MA, Gordenin DA, et al. Break-induced replication is a source of mutation clusters underlying kataegis. Cell Rep. 2014;7: 1640-1648. doi:10.1016/j.celrep.2014.04.053

29. Cahill DP, Levine KK, Betensky RA, Codd PJ, Romany CA, Reavie LB, et al. Loss of the mismatch repair protein MSH6 in human glioblastomas is associated with tumor progression during temozolomide treatment. Clin Cancer Res. 2007;13: 2038-2045. doi:10.1158/1078-0432.CCR-06-2149

30. Keung MYT, Wu Y, Vadgama JV. PARP inhibitors as a therapeutic agent for homologous recombination deficiency in breast cancers. J Clin Med. 2019;8. doi: $10.3390 / \mathrm{jcm} 8040435$

31. Cleary JM, Aguirre AJ, Shapiro GI, D'Andrea AD. Biomarker-Guided Development of DNA Repair Inhibitors. Mol Cell. 2020;78: 1070-1085. doi:10.1016/j.molcel.2020.04.035

32. Green AM, Budagyan K, Hayer KE, Reed MA, Savani MR, Wertheim GB, et al. Cytosine deaminase APOBEC3A sensitizes leukemia cells to inhibition of the DNA replication checkpoint. Cancer Res. 2017;77: 4579-4588. doi:10.1158/0008-5472.CAN-16-3394

33. Buisson R, Lawrence MS, Benes CH, Zou L. APOBEC3A and APOBEC3B activities render cancer cells susceptible to ATR inhibition. Cancer Res. 2017;77: 4567-4578. doi:10.1158/0008-5472.CAN-16-3389

34. de Bruin EC, McGranahan N, Mitter R, Salm M, Wedge DC, Yates L, et al. Spatial and temporal diversity in genomic instability processes defines lung cancer evolution. Science. 2014;346: 251-256. doi:10.1126/science.1253462

35. Chen Z, Wen W, Bao J, Kuhs KL, Cai Q, Long J, et al. Integrative genomic analyses of APOBEC-mutational signature, expression and germline deletion of APOBEC3 genes, and immunogenicity in multiple cancer types. BMC Med Genomics. 2019;12: 131. doi:10.1186/s12920-019-0579-3

36. Wang S, Jia M, He Z, Liu X-S. APOBEC3B and APOBEC mutational signature as potential predictive markers for immunotherapy response in nonsmall cell lung cancer. Oncogene. 2018;37: 3924-3936. doi:10.1038/s41388018-0245-9

37. Hustedt N, Saito Y, Zimmermann M, Álvarez-Quilón A, Setiaputra D, Adam S, et al. Control of homologous recombination by the HROB-MCM8-MCM9 pathway. Genes Dev. 2019;33: 1397-1415. doi:10.1101/gad.329508.119

38. Huang J-W, Acharya A, Taglialatela A, Nambiar TS, Cuella-Martin R, Leuzzi $\mathrm{G}$, et al. MCM8IP activates the MCM8-9 helicase to promote DNA synthesis and homologous recombination upon DNA damage. Nat Commun. 2020;11: 2948. doi:10.1038/s41467-020-16718-3

39. Griffin WC, Trakselis MA. The MCM8/9 complex: A recent recruit to the roster of helicases involved in genome maintenance. DNA Repair (Amst). 2019;76: 1-10. doi:10.1016/j.dnarep.2019.02.003

40. Ohashi E, Tsurimoto T. Functions of Multiple Clamp and Clamp-Loader Complexes in Eukaryotic DNA Replication. Adv Exp Med Biol. 2017;1042: 135-162. doi:10.1007/978-981-10-6955-0_7

41. Halabelian L, Ravichandran M, Li Y, Zeng $\bar{H}$, Rao A, Aravind L, et al. 
964

Structural basis of HMCES interactions with abasic DNA and multivalent substrate recognition. Nat Struct Mol Biol. 2019;26: 607-612.

doi:10.1038/s41594-019-0246-6

42. Mohni KN, Wessel SR, Zhao R, Wojciechowski AC, Luzwick JW, Layden H, et al. HMCES Maintains Genome Integrity by Shielding Abasic Sites in Single-Strand DNA. Cell. 2019;176: 144-153.e13. doi:10.1016/j.cell.2018.10.055

43. Thompson PS, Amidon KM, Mohni KN, Cortez D, Eichman BF. Protection of abasic sites during DNA replication by a stable thiazolidine protein-DNA cross-link. Nat Struct Mol Biol. 2019;26: 613-618. doi:10.1038/s41594-0190255-5

44. Spruijt CG, Gnerlich F, Smits AH, Pfaffeneder T, Jansen PWTC, Bauer C, et al. Dynamic readers for 5-(hydroxy)methylcytosine and its oxidized derivatives. Cell. 2013;152: 1146-1159. doi:10.1016/j.cell.2013.02.004

45. Aravind L, Anand S, lyer LM. Novel autoproteolytic and DNA-damage sensing components in the bacterial SOS response and oxidized methylcytosineinduced eukaryotic DNA demethylation systems. Biol Direct. 2013;8: 20. doi:10.1186/1745-6150-8-20

46. Wang N, Bao H, Chen L, Liu Y, Li Y, Wu B, et al. Molecular basis of abasic site sensing in single-stranded DNA by the SRAP domain of E. coli yedK. Nucleic Acids Res. 2019;47: 10388-10399. doi:10.1093/nar/gkz744

47. Colic M, Wang G, Zimmermann M, Mascall K, McLaughlin M, Bertolet L, et al. Identifying chemogenetic interactions from CRISPR screens with drugZ. Genome Med. 2019;11: 52. doi:10.1186/s13073-019-0665-3

48. Shukla V, Halabelian L, Balagere S, Samaniego-Castruita D, Feldman DE, Arrowsmith $\mathrm{CH}$, et al. HMCES Functions in the Alternative End-Joining Pathway of the DNA DSB Repair during Class Switch Recombination in B Cells. Mol Cell. 2020;77: 384-394.e4. doi:10.1016/j.molcel.2019.10.031

49. Mehta KPM, Lovejoy CA, Zhao R, Heintzman DR, Cortez D. HMCES Maintains Replication Fork Progression and Prevents Double-Strand Breaks in Response to APOBEC Deamination and Abasic Site Formation. Cell Rep. 2020;31: 107705. doi:10.1016/j.celrep.2020.107705

50. Doench JG, Fusi N, Sullender M, Hegde M, Vaimberg EW, Donovan KF, et al. Optimized sgRNA design to maximize activity and minimize off-target effects of CRISPR-Cas9. Nat Biotechnol. 2016;34: 184-191. doi:10.1038/nbt.3437

51. Li W, Köster J, Xu H, Chen C-H, Xiao T, Liu JS, et al. Quality control, modeling, and visualization of CRISPR screens with MAGeCK-VISPR. Genome Biol. 2015;16: 281. doi:10.1186/s13059-015-0843-6

52. Brown KR, Mair B, Soste M, Moffat J. CRISPR screens are feasible in TP53 wild-type cells. Mol Syst Biol. 2019;15: e8679. doi:10.15252/msb.20188679

53. Park J, Long DT, Lee KY, Abbas T, Shibata E, Negishi M, et al. The MCM8MCM9 complex promotes RAD51 recruitment at DNA damage sites to facilitate homologous recombination. Mol Cell Biol. 2013;33: 1632-1644. doi:10.1128/MCB.01503-12

54. Zhao Y, Lang G, Ito S, Bonnet J, Metzger E, Sawatsubashi S, et al. A TFTC/STAGA module mediates histone $\mathrm{H} 2 \mathrm{~A}$ and $\mathrm{H} 2 \mathrm{~B}$ deubiquitination, 
1011

1012

1013

1014

1015

1016

1017

1018

1019

1020

1021

1022

1023

1024

1025

1026

1027

1028

1029

1030

1031

1032

1033

1034

1035

1036

1037

1038

1039

1040

1041

1042

1043

1044

1045

1046

1047

1048

1049

1050

1051

1052

1053

1054

1055

1056

1057

coactivates nuclear receptors, and counteracts heterochromatin silencing.

Mol Cell. 2008;29: 92-101. doi:10.1016/j.molcel.2007.12.011

55. Lang G, Bonnet J, Umlauf D, Karmodiya K, Koffler J, Stierle M, et al. The tightly controlled deubiquitination activity of the human SAGA complex differentially modifies distinct gene regulatory elements. Mol Cell Biol.

2011;31: 3734-3744. doi:10.1128/MCB.05231-11

56. Oughtred R, Stark C, Breitkreutz B-J, Rust J, Boucher L, Chang C, et al. The BioGRID interaction database: 2019 update. Nucleic Acids Res. 2019;47: D529-D541. doi:10.1093/nar/gky1079

57. Meyers RM, Bryan JG, McFarland JM, Weir BA, Sizemore AE, Xu H, et al. Computational correction of copy number effect improves specificity of CRISPR-Cas 9 essentiality screens in cancer cells. Nat Genet. 2017;49: 1779-1784. doi:10.1038/ng.3984

58. Dempster JM, Pacini C, Pantel S, Behan FM, Green T, Krill-Burger J, et al. Agreement between two large pan-cancer CRISPR-Cas9 gene dependency data sets. Nat Commun. 2019;10: 5817. doi:10.1038/s41467-019-13805-y

59. Olivieri M, Cho T, Álvarez-Quilón A, Li K, Schellenberg MJ, Zimmermann M, et al. A genetic map of the response to DNA damage in human cells. Cell. 2020;182: 481-496.e21. doi:10.1016/j.cell.2020.05.040

60. Dempster JM, Rossen J, Kazachkova M, Pan J, Kugener G, Root DE, et al. Extracting Biological Insights from the Project Achilles Genome-Scale CRISPR Screens in Cancer Cell Lines. BioRxiv. 2019; doi:10.1101/720243

61. Ardeljan D, Steranka JP, Liu C, Li Z, Taylor MS, Payer LM, et al. Cell fitness screens reveal a conflict between LINE-1 retrotransposition and DNA replication. Nat Struct Mol Biol. 2020;27: 168-178. doi:10.1038/s41594-0200372-1

62. Jarvis MC, Ebrahimi D, Temiz NA, Harris RS. Mutation signatures including APOBEC in cancer cell lines. JNCI Cancer Spectr. 2018;2. doi:10.1093/jncics/pky002

63. Petljak M, Alexandrov LB, Brammeld JS, Price S, Wedge DC, Grossmann S, et al. Characterizing mutational signatures in human cancer cell lines reveals episodic APOBEC mutagenesis. Cell. 2019;176: 1282-1294.e20.

doi:10.1016/j.cell.2019.02.012

64. Liu Q, Yin X, Languino LR, Altieri DC. Evaluation of drug combination effect using a Bliss independence dose-response surface model. Stat Biopharm Res. 2018;10: 112-122. doi:10.1080/19466315.2018.1437071

65. Blackford AN, Jackson SP. ATM, ATR, and DNA-PK: The Trinity at the Heart of the DNA Damage Response. Mol Cell. 2017;66: 801-817. doi:10.1016/j.molcel.2017.05.015

66. Chowdhury D, Xu X, Zhong X, Ahmed F, Zhong J, Liao J, et al. A PP4phosphatase complex dephosphorylates gamma-H2AX generated during DNA replication. Mol Cell. 2008;31: 33-46. doi:10.1016/j.molcel.2008.05.016

67. Lebedeva NA, Rechkunova NI, El-Khamisy SF, Lavrik OI. Tyrosyl-DNA phosphodiesterase 1 initiates repair of apurinic/apyrimidinic sites. Biochimie. 2012;94: 1749-1753. doi:10.1016/j.biochi.2012.04.004

68. Álvarez-Quilón A, Wojtaszek JL, Mathieu M-C, Patel T, Appel CD, Hustedt N, et al. Endogenous DNA 3' blocks are vulnerabilities for BRCA1 and BRCA2 
1058

1059

1060

1061

1062

1063

1064

1065

1066

1067

1068

1069

1070

1071

1072

1073

1074

1075

1076

1077

1078

1079

1080

1081

1082

1083

1084

1085

1086

1087

1088

1089

1090

1091

1092

1093

1094

1095

1096

1097

1098

1099

1100

1101

1102

1103

1104

deficiency and are reversed by the APE2 nuclease. Mol Cell. 2020;78: 11521165.e8. doi:10.1016/j.molcel.2020.05.021

69. McNeill DR, Whitaker AM, Stark WJ, Illuzzi JL, McKinnon PJ, Freudenthal $B D$, et al. Functions of the major abasic endonuclease (APE1) in cell viability and genotoxin resistance. Mutagenesis. 2020;35: 27-38.

doi:10.1093/mutage/gez046

70. Huang J, Zhou Q, Gao M, Nowsheen S, Zhao F, Kim W, et al. Tandem Deubiquitination and Acetylation of SPRTN Promotes DNA-Protein Crosslink Repair and Protects against Aging. Mol Cell. 2020;79: 824-835.e5. doi:10.1016/j.molcel.2020.06.027

71. Halder S, Torrecilla I, Burkhalter MD, Popović M, Fielden J, Vaz B, et al. SPRTN protease and checkpoint kinase 1 cross-activation loop safeguards DNA replication. Nat Commun. 2019;10: 3142. doi:10.1038/s41467-01911095-y

72. Kalev P, Simicek M, Vazquez I, Munck S, Chen L, Soin T, et al. Loss of PPP2R2A inhibits homologous recombination DNA repair and predicts tumor sensitivity to PARP inhibition. Cancer Res. 2012;72: 6414-6424.

doi:10.1158/0008-5472.CAN-12-1667

73. Goodarzi AA, Jonnalagadda JC, Douglas P, Young D, Ye R, Moorhead GBG, et al. Autophosphorylation of ataxia-telangiectasia mutated is regulated by protein phosphatase 2A. EMBO J. 2004;23: 4451-4461.

doi:10.1038/sj.emboj.7600455

74. Ruvolo PP. The broken "Off" switch in cancer signaling: PP2A as a regulator of tumorigenesis, drug resistance, and immune surveillance. BBA Clin. 2016;6: 87-99. doi:10.1016/j.bbacli.2016.08.002

75. Serebrenik AA, Starrett GJ, Leenen S, Jarvis MC, Shaban NM, Salamango DJ, et al. The deaminase APOBEC3B triggers the death of cells lacking uracil DNA glycosylase. Proc Natl Acad Sci USA. 2019;116: 22158-22163. doi:10.1073/pnas.1904024116

76. Srivastava M, Su D, Zhang H, Chen Z, Tang M, Nie L, et al. HMCES safeguards replication from oxidative stress and ensures error-free repair. EMBO Rep. 2020;21: e49123. doi:10.15252/embr.201949123

77. Tsherniak A, Vazquez F, Montgomery PG, Weir BA, Kryukov G, Cowley GS, et al. Defining a cancer dependency map. Cell. 2017;170: 564-576.e16. doi:10.1016/j.cell.2017.06.010

78. Sherr CJ, Bartek J. Cell cycle?targeted cancer therapies. Annu Rev Cancer Biol. 2017;1: 41-57. doi:10.1146/annurev-cancerbio-040716-075628

79. Qiu Z, Fa P, Liu T, Prasad CB, Ma S, Hong Z, et al. A Genome-Wide Pooled shRNA Screen Identifies PPP2R2A as a Predictive Biomarker for the Response to ATR and CHK1 Inhibitors. Cancer Res. 2020;80: 3305-3318. doi:10.1158/0008-5472.CAN-20-0057

80. Kawale AS, Povirk LF. Tyrosyl-DNA phosphodiesterases: rescuing the genome from the risks of relaxation. Nucleic Acids Res. 2018;46: 520-537. doi:10.1093/nar/gkx1219

81. Wang B, Wang M, Zhang W, Xiao T, Chen C-H, Wu A, et al. Integrative analysis of pooled CRISPR genetic screens using MAGeCKFlute. Nat Protoc. 2019;14: 756-780. doi:10.1038/s41596-018-0113-7 
82. Hart T, Brown KR, Sircoulomb F, Rottapel R, Moffat J. Measuring error rates in genomic perturbation screens: gold standards for human functional genomics. Mol Syst Biol. 2014;10: 733. doi:10.15252/msb.20145216

83. Hart T, Tong AHY, Chan K, Van Leeuwen J, Seetharaman A, Aregger M, et al. Evaluation and Design of Genome-Wide CRISPR/SpCas9 Knockout Screens. G3 (Bethesda). 2017;7: 2719-2727. doi:10.1534/g3.117.041277

84. Spandidos A, Wang X, Wang H, Seed B. PrimerBank: a resource of human and mouse PCR primer pairs for gene expression detection and quantification. Nucleic Acids Res. 2010;38: D792-9. doi:10.1093/nar/gkp1005 


\section{Supporting Information}

1126

1127

1128
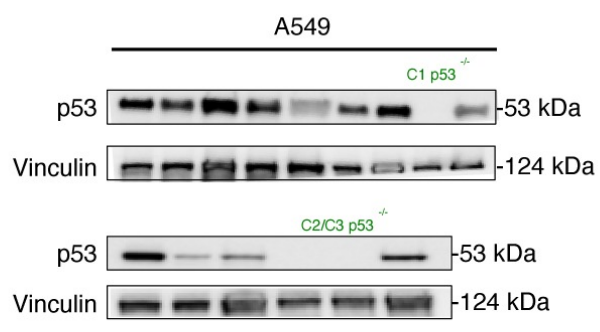

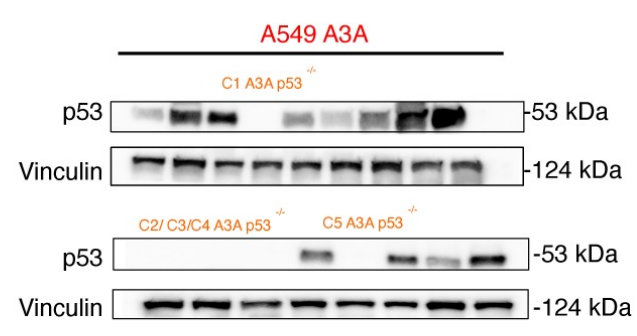

1130 S1 Fig. Validation of the A549 \pm A3A TP53-/- clones. Western blot of the A549

1131 p53-/- (left panel) and the A549 A3A transduced p53-/- clones (right panel)

1132 generated using CRISPR/Cas9 targeting.
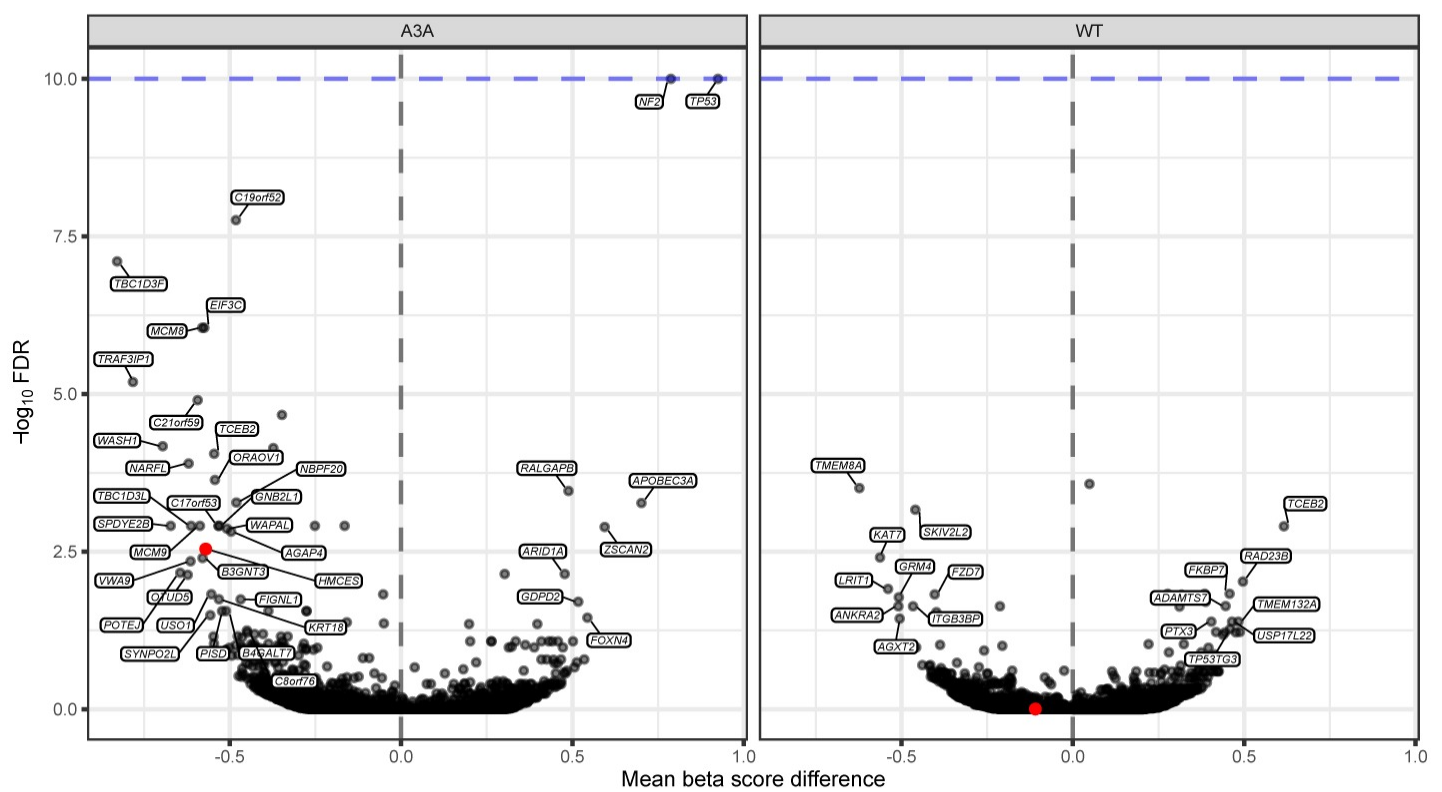

1135

1136 S2 Fig. Effects of DOX treatment. Volcano plot highlighting genes for which there

1137 could exist interaction with DOX per se. The x-axis represents the difference of the 
1138 (normalized) MAGeCK-MLE's beta score between treating a sample with DOX $\left(\mathrm{IC}_{25}\right)$

1139 and the corresponding control sample, averaged across the A3A plasmid-free

1140 version of all cell lines sampled after 15 days of cell culture. Intuitively, genes with

1141 significant negative beta score differences suggest conditional essentiality with

1142 DOX. The y-axis represents the - $\log _{10}$ FDR of the Fisher's combined $p$-value (either

1143 lower

A
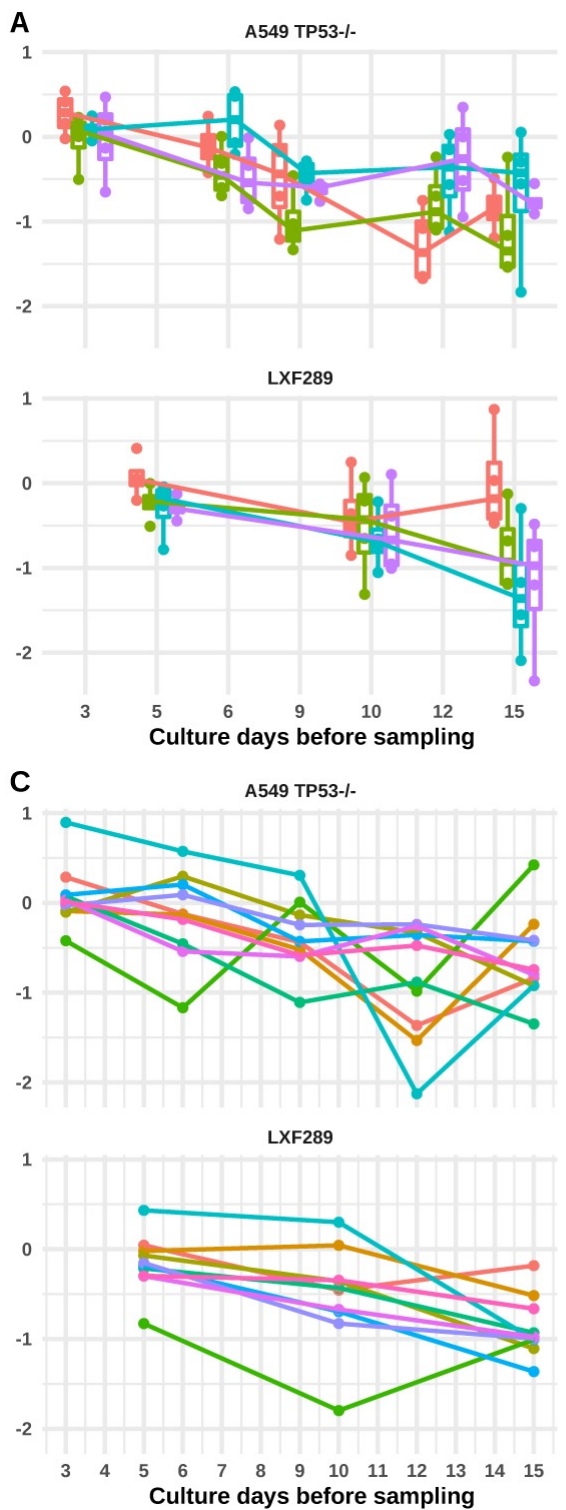

tail)

B

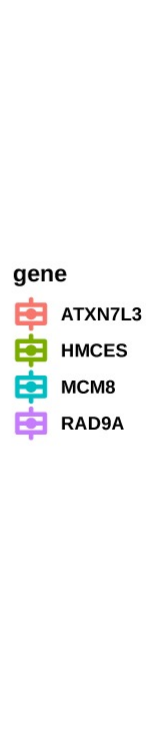

gene

$\because$ ATXN7L3

$\because \mathrm{CDC} 23$

$\rightarrow$ DDX11

$\sim$ HGC6.3

$\sim$ HMCES

$\sim$ KPNB1

- MCM8

$\approx$ MCM9

$\rightarrow$ RAD9A

- UBAG

D
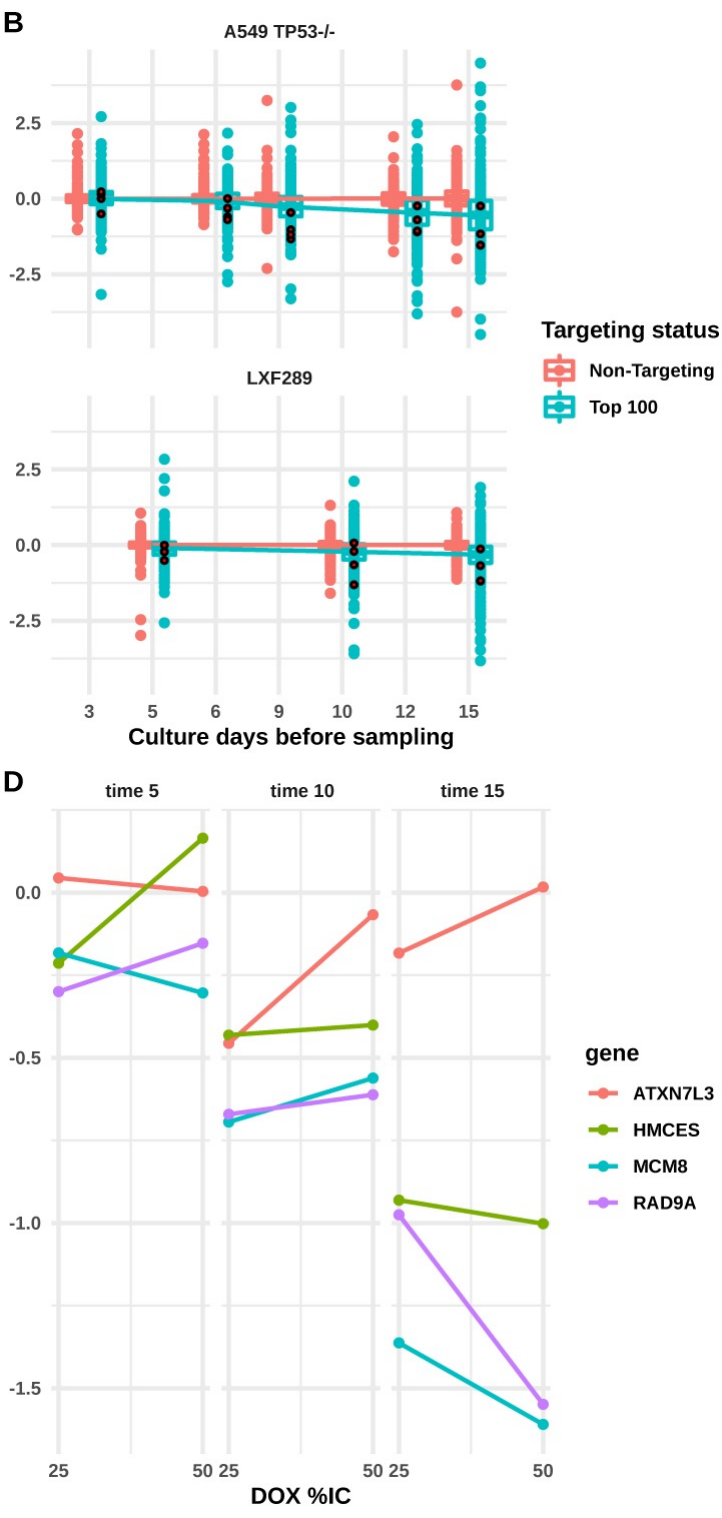

1145 S3 Fig. Change in sgRNA count LFC dependent on days of cell culture before 
1146 sampling or DOX dose. LFC (y-axes) represents the cell count differences between

1147 a sample treated with $\mathrm{DOX}\left(\mathrm{IC}_{25}\right.$ in plots $\mathrm{a}, \mathrm{b}$, and $\left.\mathrm{c}\right)$ and the corresponding control

1148 (untreated) sample. (A) The top four genes are shown after sorting based on the

1149 overall score. The four sgRNAs targeting each gene are shown separately, and their

1150 count distribution is represented as a boxplot. Lines join the median sgRNA counts

1151 for each gene. One of the top-5 genes, HGC6.3, was excluded from the plot due to

1152 low data quality (see S1 Table). (B) The sgRNAs shown are the 1000 non-targeting

1153 control sgRNAs in the Brunello library[50], and the top 100 genes after sorting genes

1154 based on the overall score. Lines join the median sgRNA counts for each distribution.

1155 Red dots indicate the LFC of sgRNAs for the HMCES gene. (C) The top ten genes

1156 are shown after sorting by the overall score. Here, the HGC6.3 gene is included,

1157 while according to MAGeCK-MLE it had low sgRNA efficiency (S1 Table), possibly

1158 causing the rather erratic trends across time points that it exhibits. (D) Difference in

1159 LFC dependent on DOX dose, either $\mathrm{IC}_{25}$ or $\mathrm{IC}_{50}$, in the $\mathrm{LXF289}$ cell line. Columns

1160 show LFCs at different sampling times. The top four genes by overall score are

1161 shown.

1162

1163

\begin{tabular}{|l|l|l|l|l|l|l|l|l|}
\hline Gene & sgRNA & Cell line & Efficiency & Gene & sgRNA & Cell line & Efficiency \\
\hline & s_75152 & A549 TP53-/- & 1 & & & s_42031 & A549 TP53-/- & 1 \\
\hline & & LXF289 & 0.727 & & & & LXF289 & 1 \\
\hline HGC6.3 & s_75153 & A549 TP53-/- & 1 & & & s_42032 & A549 TP53-/- & 1 \\
\hline & LXF289 & 0.596 & UBA6 & & LXF289 & 1 \\
\hline & s_75154 & A549 TP53-/- & 0.977 & & & s_42033 & A549 TP53-/- & 1 \\
\hline & s_75155 & A549 TP53-/- & 1 & & & & LXF289 & 1 \\
\hline
\end{tabular}


bioRxiv preprint doi: https://doi.org/10.1101/2021.02.05.429803; this version posted February 6, 2021. The copyright holder for this preprint (which was not certified by peer review) is the author/funder, who has granted bioRxiv a license to display the preprint in perpetuity. It is made available under aCC-BY-NC 4.0 International license.

\begin{tabular}{|c|c|c|c|c|c|c|c|}
\hline & & LXF289 & 0.644 & & & LXF289 & 1 \\
\hline & s_44647 & A549 TP53-/- & 1 & & s_4665 & A549 TP53-/- & 1 \\
\hline & & LXF289 & 1 & & & LXF289 & 1 \\
\hline & s_44648 & A549 TP53-/- & 1 & & s_4666 & A549 TP53-/- & 0.975 \\
\hline \multirow[t]{8}{*}{ HMCES } & & LXF289 & 1 & $D D \times 11$ & & LXF289 & 1 \\
\hline & s_44649 & A549 TP53-/- & 1 & & s_4667 & A549 TP53-/- & 0.713 \\
\hline & & LXF289 & 0.992 & & & LXF289 & 0.999 \\
\hline & s_44650 & A549 TP53-/- & 1 & & s_4668 & A549 TP53-/- & 0.968 \\
\hline & & LXF289 & 1 & & & LXF289 & 1 \\
\hline & s_15717 & A549 TP53-/- & 1 & & s_66465 & A549 TP53-/- & 0.996 \\
\hline & & LXF289 & 1 & & & LXF289 & 0.973 \\
\hline & s_15718 & A549 TP53-/- & 1 & & s_66466 & A549 TP53-/- & 0.998 \\
\hline \multirow[t]{8}{*}{ RAD9A } & & LXF289 & 1 & МСM9 & & LXF289 & 1 \\
\hline & s_15719 & A549 TP53-/- & 1 & & s_66467 & A549 TP53-/- & 0.79 \\
\hline & & LXF289 & 1 & & & LXF289 & 1 \\
\hline & s_15720 & A549 TP53-/- & 1 & & s_66468 & A549 TP53-/- & 1 \\
\hline & & LXF289 & 1 & & & LXF289 & 1 \\
\hline & s_53711 & A549 TP53-/- & 1 & & s_22709 & A549 TP53-/- & 1 \\
\hline & & LXF289 & 1 & & & LXF289 & 1 \\
\hline & s_53712 & A549 TP53-/- & 0.956 & & s_22710 & A549 TP53-/- & 1 \\
\hline \multirow[t]{8}{*}{ МСМ8 } & & LXF289 & 0.999 & $C D C 23$ & & LXF289 & 1 \\
\hline & s_53713 & A549 TP53-/- & 0.937 & & s_22711 & A549 TP53-/- & 1 \\
\hline & & LXF289 & 1 & & & LXF289 & $1.22 \mathrm{E}-13$ \\
\hline & s_53714 & A549 TP53-/- & 0.976 & & s_22712 & A549 TP53-/- & 1 \\
\hline & & LXF289 & 1 & & & LXF289 & 1 \\
\hline & s_44735 & A549 TP53-/- & 1 & & S_28149 & A549 TP53-/- & 1 \\
\hline & & LXF289 & 1 & & & LXF289 & 1 \\
\hline & s_44736 & A549 TP53-/- & 1 & & s_28150 & A549 TP53-/- & 1 \\
\hline \multirow[t]{2}{*}{ ATXN7L3 } & & LXF289 & 1 & $M A D 2 L 2$ & & LXF289 & 1 \\
\hline & s_44737 & A549 TP53-/- & 1 & & s_28151 & A549 TP53-/- & 1 \\
\hline
\end{tabular}




\section{4}

1165

1166 sgRNAs were estimated by the MAGeCK-MLE algorithm in A549TP53-/- and LXF-289

1167 cell lines. Informally, the efficiencies estimate the probability that a given sgRNA is

1168 able to generate an inactivating double-strand DNA break in the targeted gene. Only

1169 the HGC6.3 gene shows overall low sgRNA efficiencies, particularly in the LXF-289

1170 cell line, suggesting that the high log-fold change scores therein are an artefact (S3

1171 Fig). HMCES has near-perfect sgRNA efficiencies. 


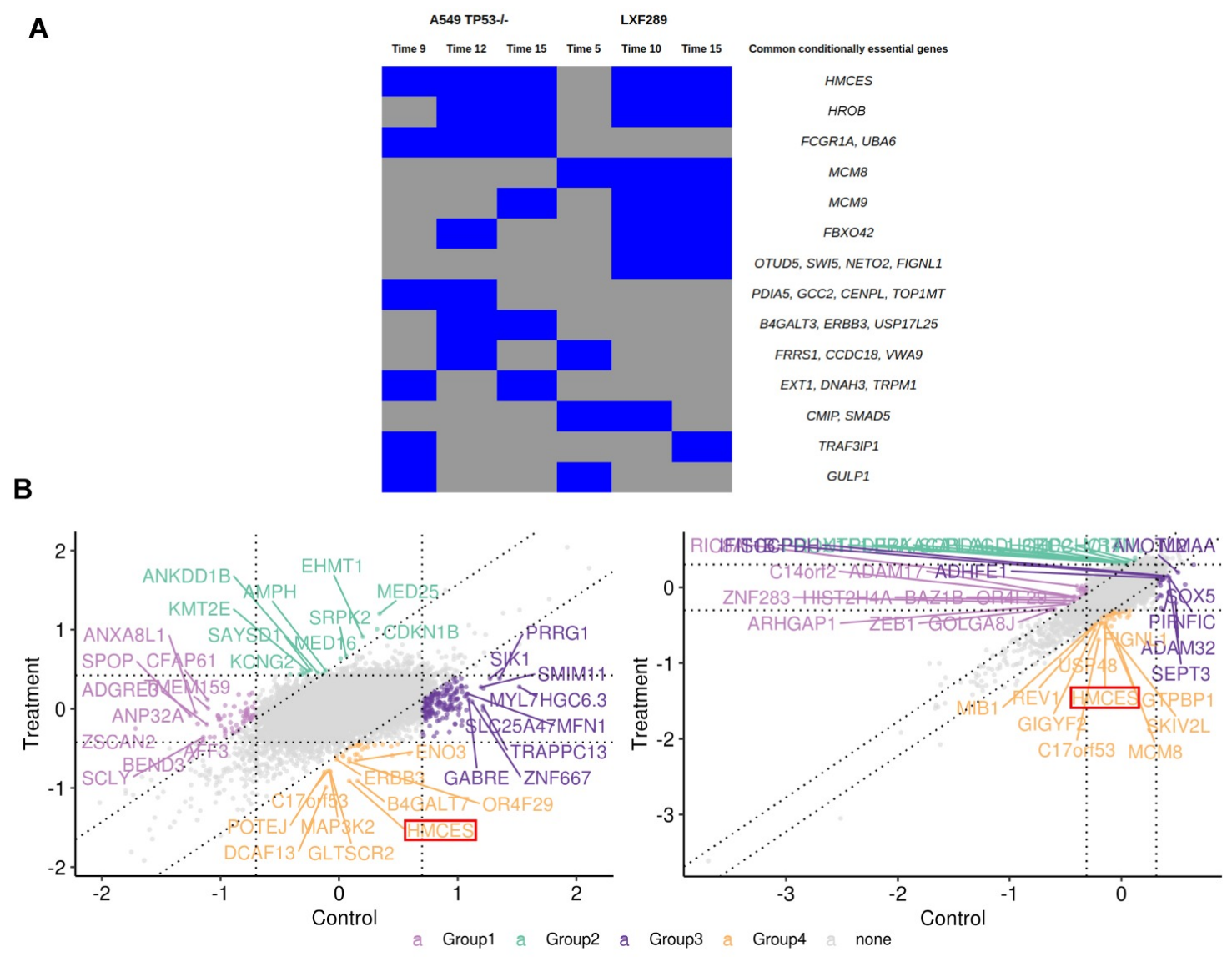

S4 Fig. Analysis of genetic screening data using an additional statistical

1174 methodology (MAGeCK-MLE). (A) Out of a total of 339 genes identified as

1175 conditionally essential by MAGeCK-MLE in either of the two cell lines examined (see

1176 next point), this figure shows those genes that were significant in more than one

1177 sample (time point / cell line combination). A blue box indicates that the genes in that

1178 row are conditionally essential (under A3A overexpression) in the corresponding

1179 sample, while a gray box indicates that there is no significant essentiality. HMCES

1180 is the gene found to be conditionally essential in the highest number samples -- all

1181 samples except the earliest time point of LXF-289, time 5. (B) MAGeCK-MLE

1182 visualizations ('nine-square plots' as in[81]) based on (left) A549 TP53-/- and (right)

1183 LXF-289 cell lines, both sampled at day 15. Points represent genes distributed 
1184 according to the between-samples normalized beta scores (enrichments) for the

1185 control sample (untreated, $\mathrm{x}$-axis) and DOX-treated sample (at $\mathrm{IC}_{25}$ concentration,

1186 y-axis). Vertical and horizontal dotted lines indicate two standard deviations of the

1187 beta score distribution away from zero to each side. Analogously, diagonal dotted

1188 lines represent two standard deviations of the distribution of between-treatment beta

1189 score differences away from zero to each side. Therefore, genes located in the

1190 bottom center square (“Group4” genes) have MAGeCK beta scores different

1191 between the control and treated sample, being not different from zero in the control

1192 (i.e. no evidence of selection) but significantly negative in the treatment (i.e.

1193 negatively selected); in other words, these genes are conditionally selected under

1194 A3A overexpression (DOX-induced). The top 10 genes are labeled in each square.

1195 HMCES is a top hit in both cell lines. 


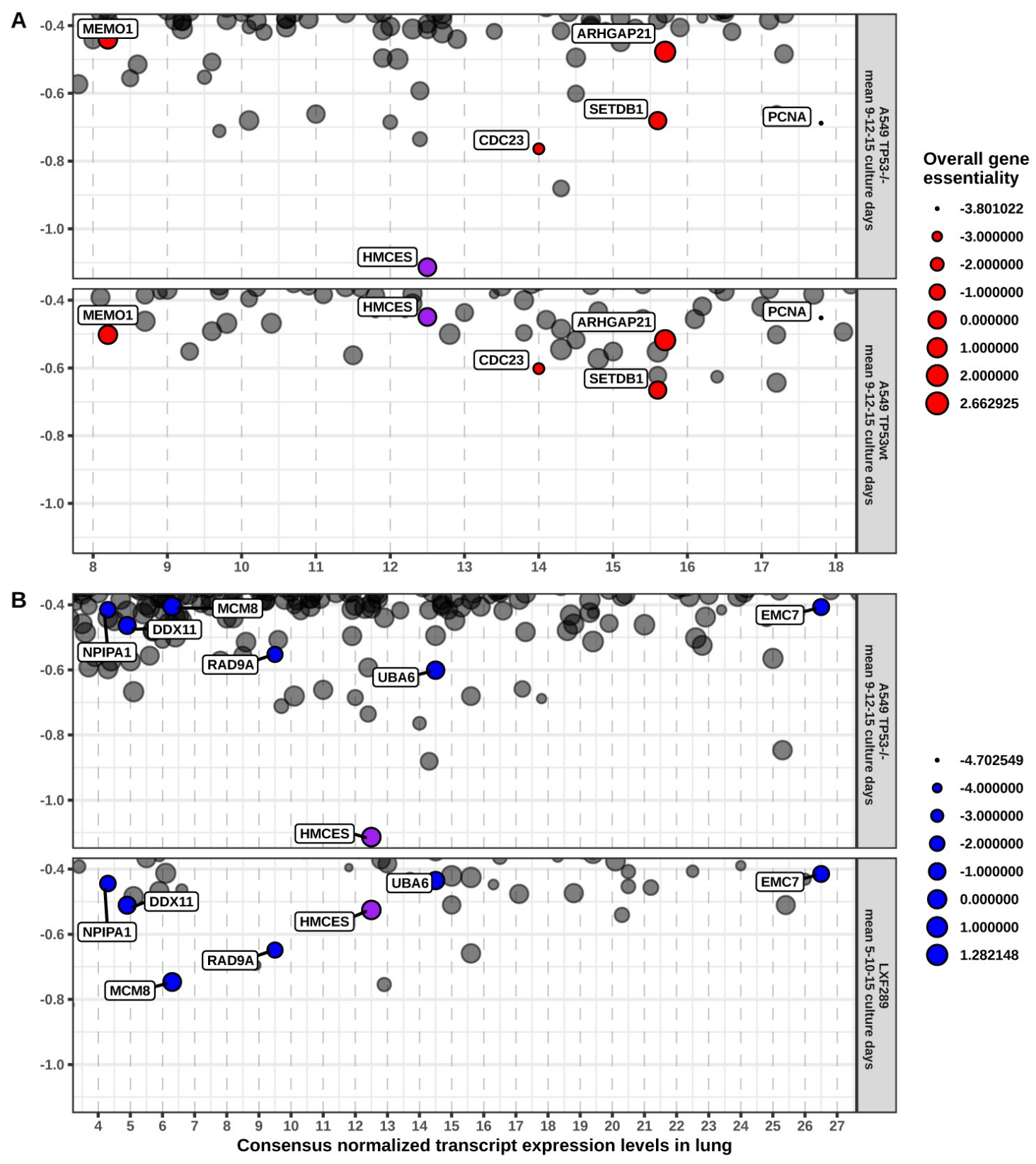

S5 Fig. Contrasts of A3A-conditionally essential genes between different

1199 genetic backgrounds. (A) Contrast between TP53 backgrounds of the A549 cell

1200 line. Red circles are genes with a consistently strong negative LFC (below -0.4) in

1201 both TP53 backgrounds (-/- above, wild-type below), considering the mean LFC after

12029,12 , and 15 culture days (y-axes); LFC represents the cell count differences 
1203 between a sample treated with $\mathrm{DOX}\left(\mathrm{IC}_{25}\right)$ and the corresponding control (untreated)

1204 sample. The circle area shows the beta score (enrichment) calculated with

1205 MAGeCK-MLE and averaged across the time points: a more negative beta score

1206 indicates stronger gene essentiality irrespective of treatment. X-axes represent the

1207 Human Protein Atlas consensus normalized (across cell lines) transcript expression

1208 levels (NX) in lung tissue for each gene. Among the hits, HMCES is prominent in the

1209 TP53-/- background but not in the wild-type background, has moderate expression

1210 levels in lung tissue, and does not appear to be generally strongly essential. (B) In

1211 an analogous manner, this plot shows the contrast of A3A-conditionally essential

1212 genes between the A549 ${ }^{\text {TP53-- }}$ and the LXF-289 genetic backgrounds; here, blue

1213 circles are genes with a consistently strong negative LFC (below -0.4) in both cell

1214 lines. Among the hits, HMCES, RAD9A and, to some extent, MCM8 appear

1215 consistent in both backgrounds; of these three genes, HMCES has somewhat higher

1216 expression levels in lung tissue, and is the least essential in these cell lines. HMCES

1217 is the only hit that is consistent in both comparisons, and this is noted by using a

1218 purple color to highlight it.

1220 See excel file.

1221 S2 Table. Gene-level data for all primary screens.

1223 See excel file.

1224 S3 Table. Enriched GO Biological Process terms obtained from GOrilla. GOrilla

1225 (http://cbl-gorilla.cs.technion.ac.il/) was used to analyze gene ontology using a P- 
1226 value threshold set at $10^{-3}$. Samples included are A549 TP53-/- at time points 9, 12, and 122715 days, and LXF-289 at time points 5,10 , and 15 days.

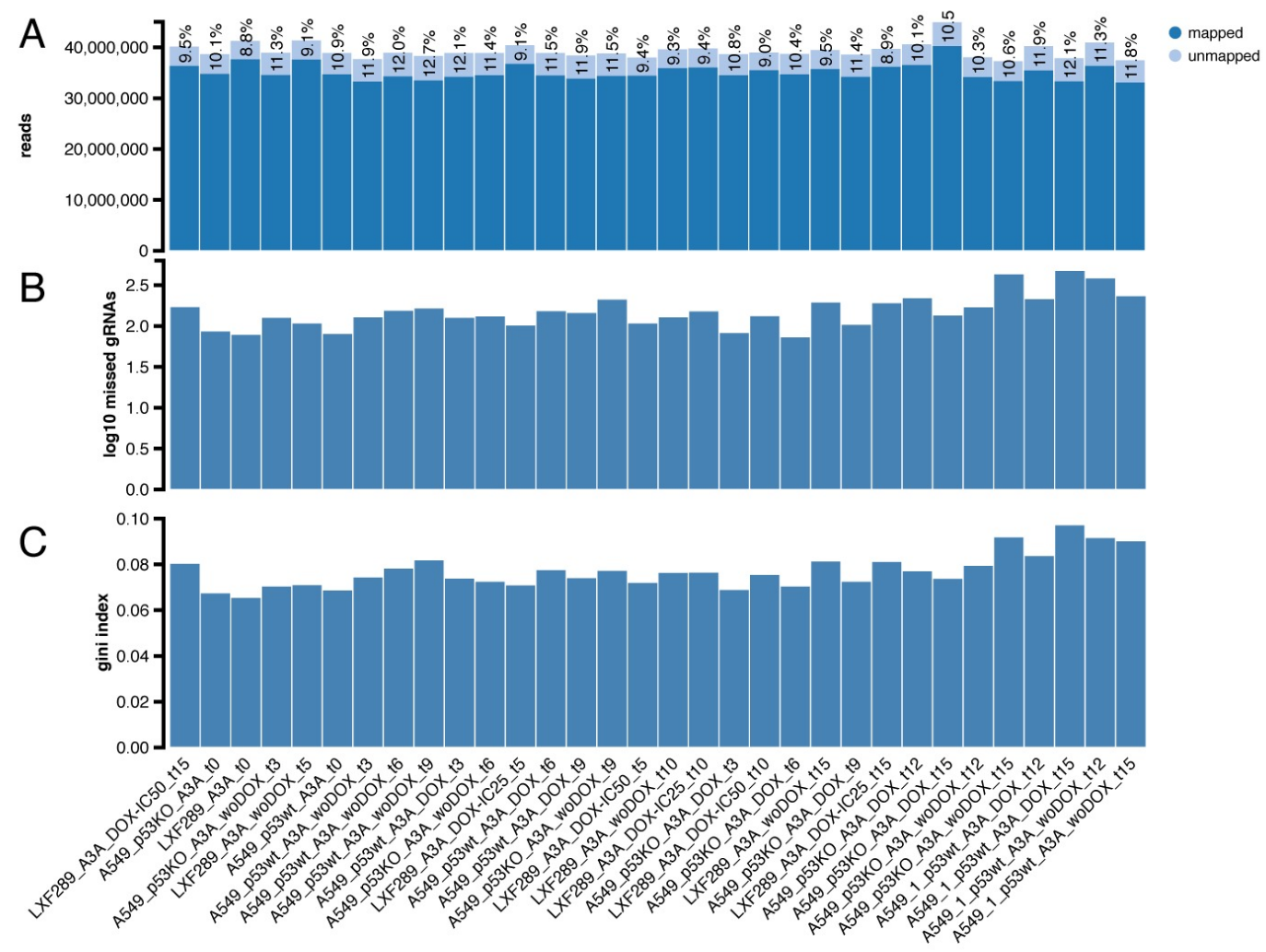

S6 Fig. Quality control of sequencing reads. (A) Number of total sequenced reads

1230 per sample. Light blue fraction represents the percentage of reads that are

1231 unequivocally unmapped to the library, which is below the recommended maximum

1232 of $35 \%$ in all samples[51]. (B) Number of library sgRNAs that have zero counts per

1233 sample. Figures are higher in late samples, but this is to be expected due to negative

1234 selection. Overall, sgRNAs with zero counts are $<1 \%$ of total sgRNAs in Brunello

1235 library $(\sim 77 \mathrm{~K})[50,51]$. Namely, the maximum number of sgRNAs is 461 . (C) Gini 1236 index of log-scaled read count distributions. This measure of the evenness across

1237 all sgRNA counts is below the recommended maximum of 0.2 in all samples[51].

1238 Also, the Gini index is expected to increase in later time points. 


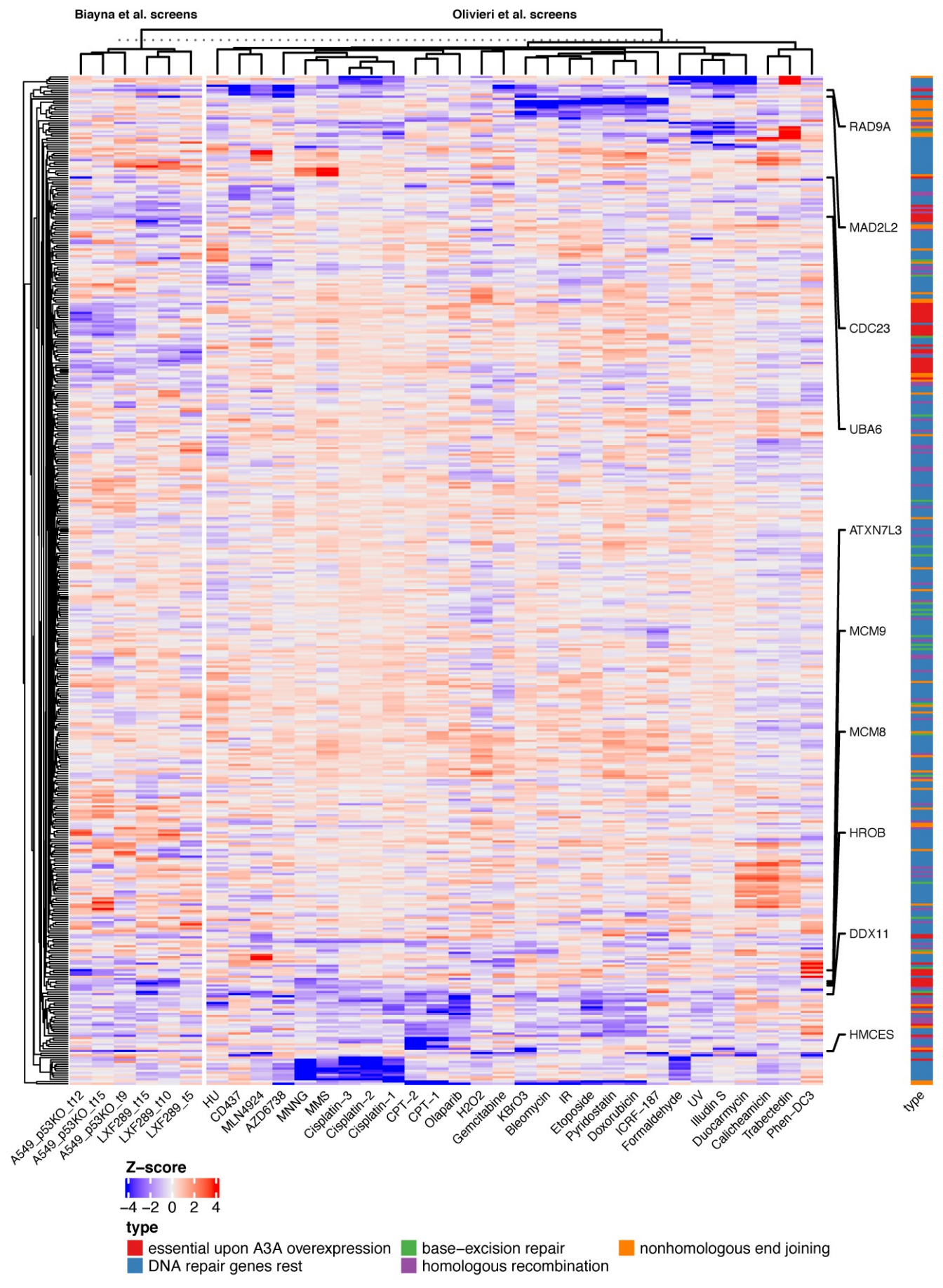

1240 S7 Fig. Many APOBEC-sensitizing genes, but not HMCES, also sensitize to a 1241 variety of other DNA damaging agents. Left panel of heatmap shows a gene-level

1242 normalized log2 fold change (gene essentiality score) upon A3A overexpression for 
1243 two cell lines and for three time points (Biayna et al. screens); right panel shows Z-

1244 scores of gene essentiality after genotoxin exposure (Olivieri et al. screens)[59].

1245 Data for 50 genes that are essential upon A3A overexpression in our screens (i.e.

1246 genes with the most negative mean log2 fold change across six data points) (labelled

1247 "top"), and 521 DNA repair genes. Labels on the right-hand side highlight the ten

1248 genes showing the highest overall A3A essentiality.

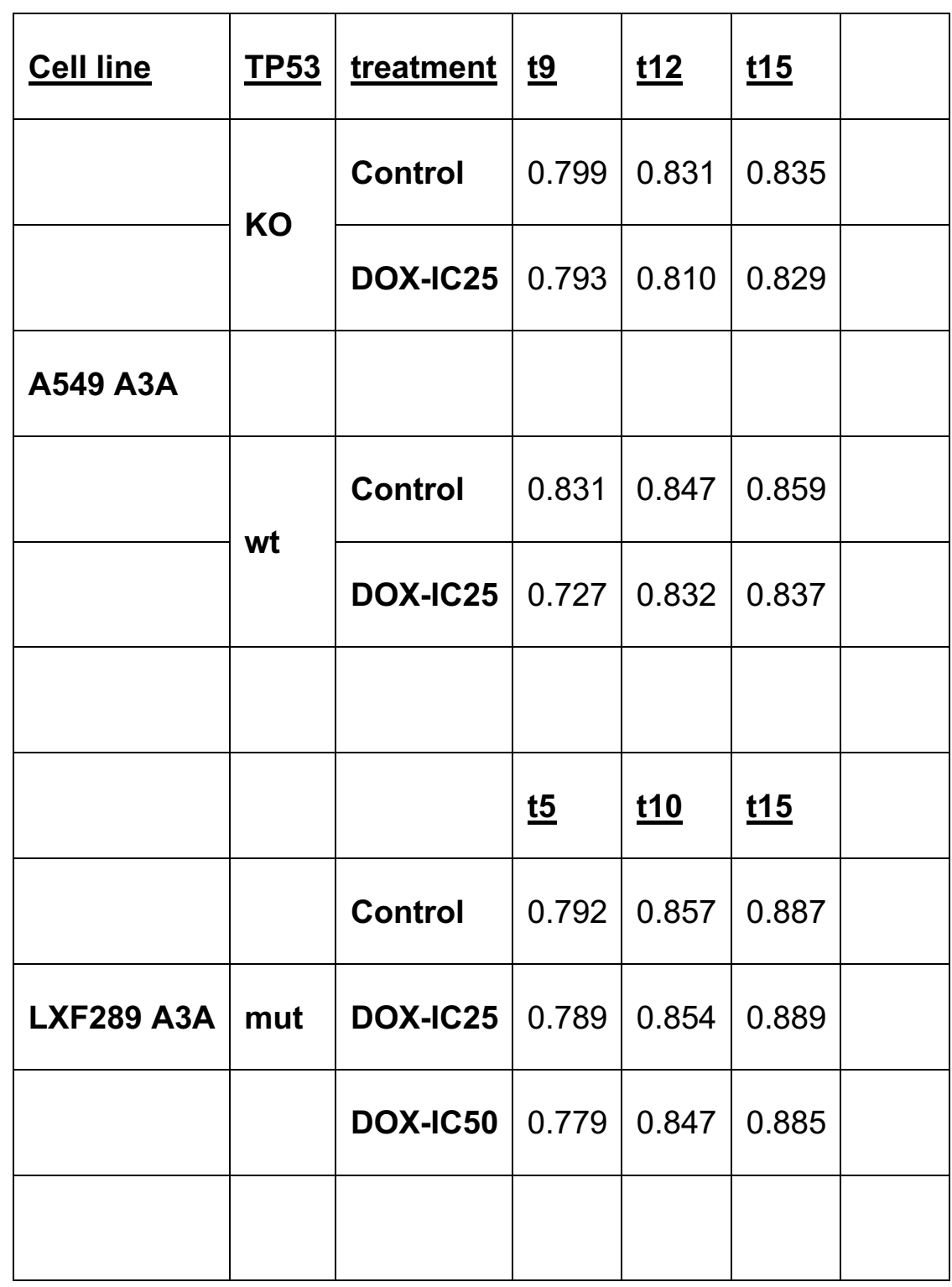




\begin{tabular}{|l|l|l|l|l|l|l|}
\hline & & & $\underline{\mathbf{t}}$ & $\underline{\mathbf{t 1 2}}$ & $\underline{\mathbf{t} 15}$ & $\underline{\mathbf{t} 18}$ \\
\hline & KO & & & & & 0.881 \\
\hline RPE1[52] & & & & & & \\
\hline & wt & & 0.850 & 0.877 & 0.881 & 0.895 \\
\hline
\end{tabular}

S4 Table. Area under the receiving operating characteristic curves (AUC) of

1253 each sample. AUC per sample, based on the capacity of the CRISPR screening to

1254 discriminate between known sets of essential[81-83] and non-essential[82] genes

1255 by their normalized read counts. For comparison, the AUCs for the same overall sets

1256 of genes in the genetic screens (RPE1 cell line) from Brown et al. 2019[52] have

1257 been included: note that, while our screening was based on the Brunello library[50],

1258 Brown et al. employed the TKO library, so the gene overlap is not total.

\begin{tabular}{|l|l|l|l|l|}
\hline gene & signature & $\begin{array}{l}\text { Regression } \\
\text { coefficient }\end{array}$ & $\begin{array}{l}\text { p-value } \\
\text { (two- } \\
\text { tailed) }\end{array}$ & $\begin{array}{l}\text { pvalue } \\
\text { (one-tailed, lower i.e. signature } \\
\text { sensitizes to gene k.o.) }\end{array}$ \\
\hline HMCES & SBS2 & -0.499 & 0.095 & 0.048 \\
\hline UBA6 & SBS2 & -0.666 & 0.113 & 0.057 \\
\hline HMCES & SBS13+2 & -0.197 & 0.122 & 0.061 \\
\hline HMCES & SBS13 & -0.288 & 0.171 & 0.085 \\
\hline UBA6 & SBS13+2 & -0.238 & 0.186 & 0.093 \\
\hline UBA6 & SBS13 & -0.314 & 0.287 & 0.144 \\
\hline KPNB1 & SBS13 & -0.260 & 0.469 & 0.234 \\
\hline MCM8 & SBS13 & -0.080 & 0.774 & 0.387 \\
\hline MCM8 & SBS13+2 & -0.047 & 0.783 & 0.392 \\
\hline KPNB1 & SBS13+2 & -0.054 & 0.806 & 0.403 \\
\hline MCM8 & SBS2 & -0.094 & 0.814 & 0.407 \\
\hline DDX11 & SBS2 & -0.018 & 0.969 & 0.485 \\
\hline RAD9A & SBS13 & 0.018 & 0.965 & 0.517 \\
\hline
\end{tabular}




\begin{tabular}{|l|l|l|l|l|}
\hline ATXN7L3 & SBS13 & 0.021 & 0.963 & 0.518 \\
\hline ATXN7L3 & SBS13+2 & 0.038 & 0.893 & 0.553 \\
\hline DDX11 & SBS13+2 & 0.038 & 0.847 & 0.576 \\
\hline ATXN7L3 & SBS2 & 0.166 & 0.803 & 0.598 \\
\hline RAD9A & SBS13+2 & 0.075 & 0.766 & 0.617 \\
\hline DDX11 & SBS13 & 0.113 & 0.731 & 0.634 \\
\hline KPNB1 & SBS2 & 0.236 & 0.646 & 0.677 \\
\hline MCM9 & SBS13 & 0.144 & 0.554 & 0.723 \\
\hline RAD9A & SBS2 & 0.374 & 0.524 & 0.738 \\
\hline MCM9 & SBS13+2 & 0.099 & 0.507 & 0.746 \\
\hline MCM9 & SBS2 & 0.247 & 0.478 & 0.761 \\
\hline MAD2L2 & SBS2 & 0.544 & 0.458 & 0.771 \\
\hline CDC23 & SBS13 & 0.331 & 0.331 & 0.834 \\
\hline MAD2L2 & SBS13+2 & 0.328 & 0.293 & 0.854 \\
\hline MAD2L2 & SBS13 & 0.618 & 0.227 & 0.886 \\
\hline CDC23 & SBS13+2 & 0.261 & 0.208 & 0.896 \\
\hline CDC23 & SBS2 & 0.760 & 0.117 & 0.942 \\
\hline
\end{tabular}

1262 S5 Table. Table of differential fitness scores. Differential fitness scores (from

1263 project Achilles) upon APOBEC mutational signatures (SBS2, SBS13 and SBS13+2)

1264 burden for the top 10 genes that are essential upon A3A overexpression in our 1265 screens (i.e. genes with the most negative mean log2 fold change across six data 1266 points).

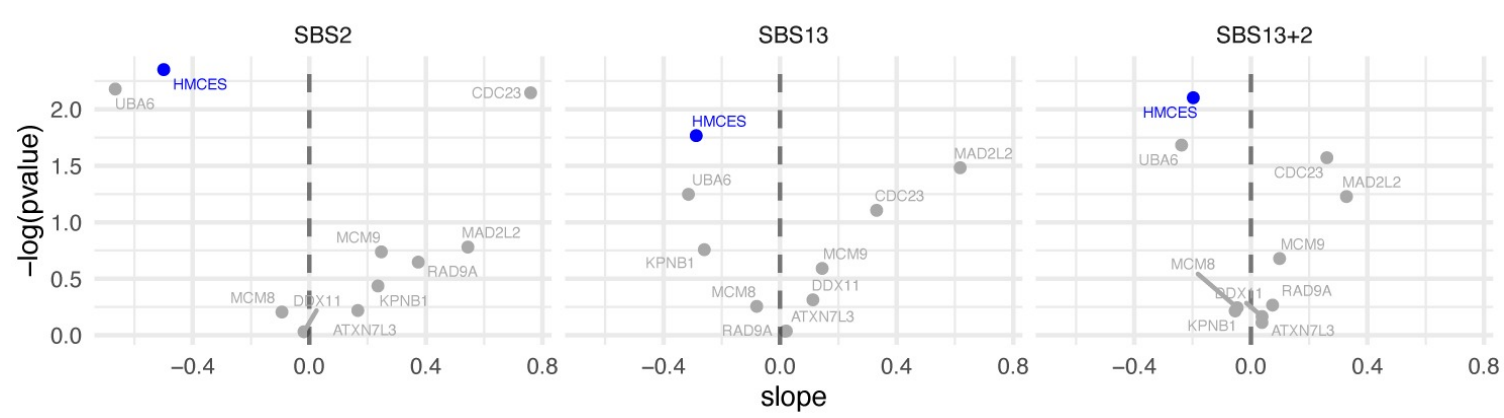

S8 Fig. Differential fitness scores. Differential fitness score (from project Achilles) 1272 upon APOBEC mutational signatures burden for the top 10 genes that are essential 
upon A3A overexpression in our screens (i.e. genes with the most negative mean $\log 2$ fold change across six data points).
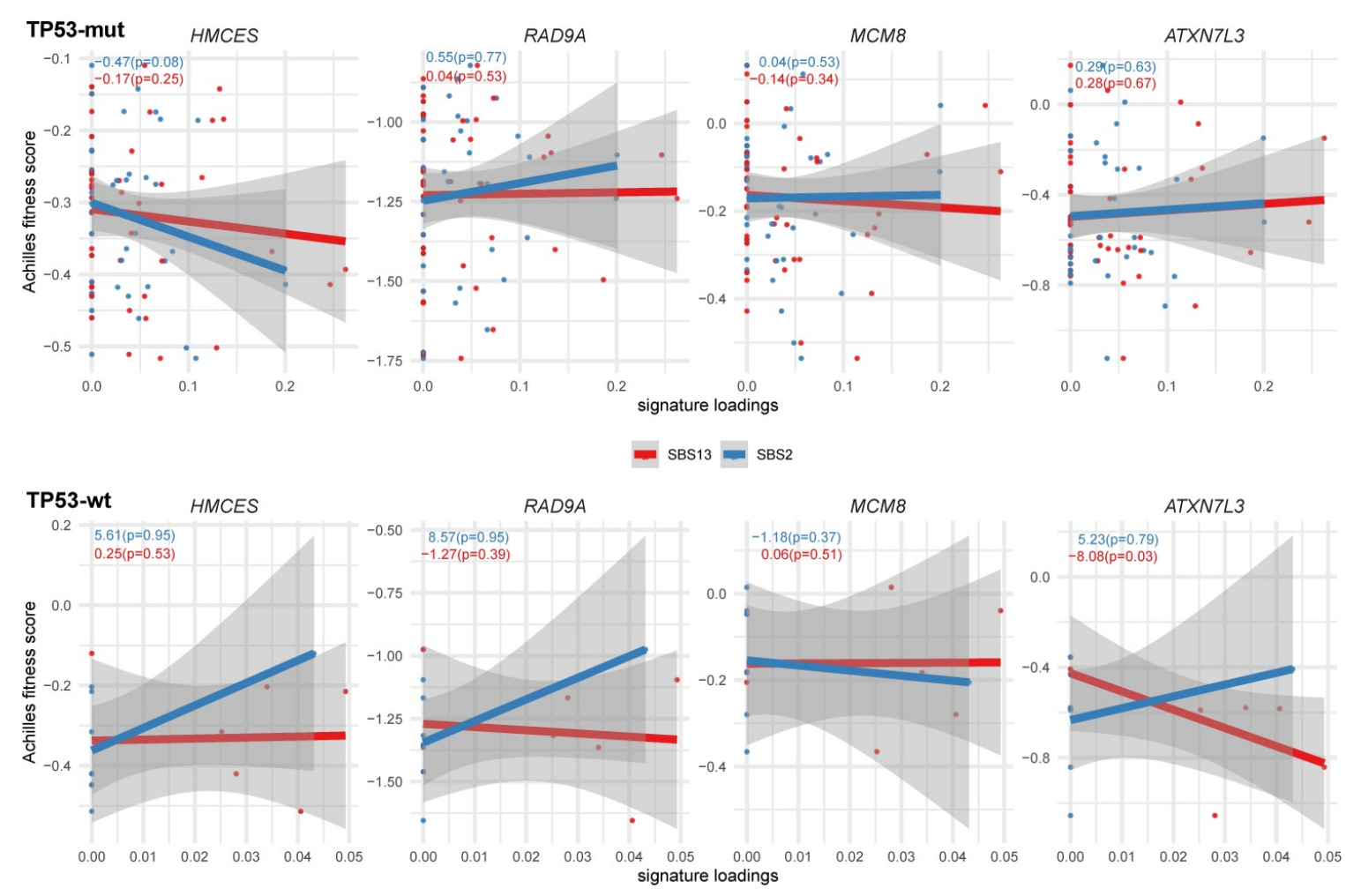

S9 Fig. Gene essentiality fitness score from project Achilles versus APOBEC

1278 mutational signatures exposures. Cell lines originating from head-and-neck

1279 squamous cell carcinoma, lung adenocarcinoma, and lung squamous cell carcinoma

1280 were analyzed for the four genes with the greatest overall score in our genetic 1281 screens, while examining TP53 mutated (mut) and TP53 wild-type (wt) cell lines

1282 separately. The slope and p-value (one-tailed, lower) for the regression model for 1283 both APOBEC mutational signatures are shown within each panel. The more 1284 negative the slope, the more sensitive the cell lines are to the depletion of the 1285 particular gene at a higher level of the APOBEC mutational signature. 

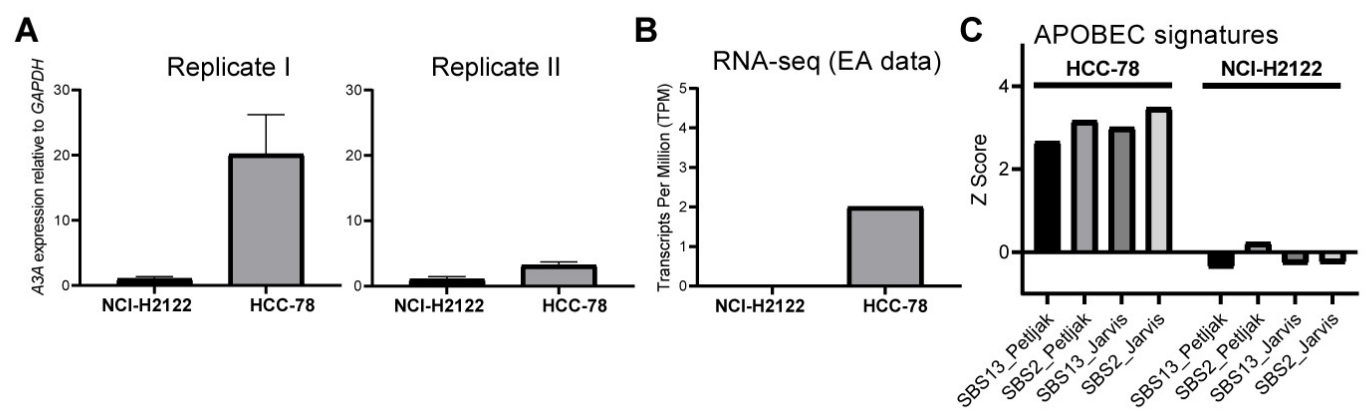

1288 S10 Fig. Endogenous expression and A3-mutational signature status of cell

1289 lines. (A) Endogenous $A 3 A$ mRNA expression levels in $\mathrm{HCC}-78$ and $\mathrm{NCl}-\mathrm{H} 2122$

1290 cells relative to GAPDH measured by quantitative real-time PCR (two independent

1291 biological replicates). (B) A3A gene expression (TPMs) downloaded from expression

1292 atlas (EA; https://www.ebi.ac.uk/gxa/home) and (C) APOBEC mutational

1293 signatures (SBS2 and SBS13) burden downloaded from Petljak et al. and Jarvis et.

1294 al and normalized across cell lines (z-score)[62,63]. 
A

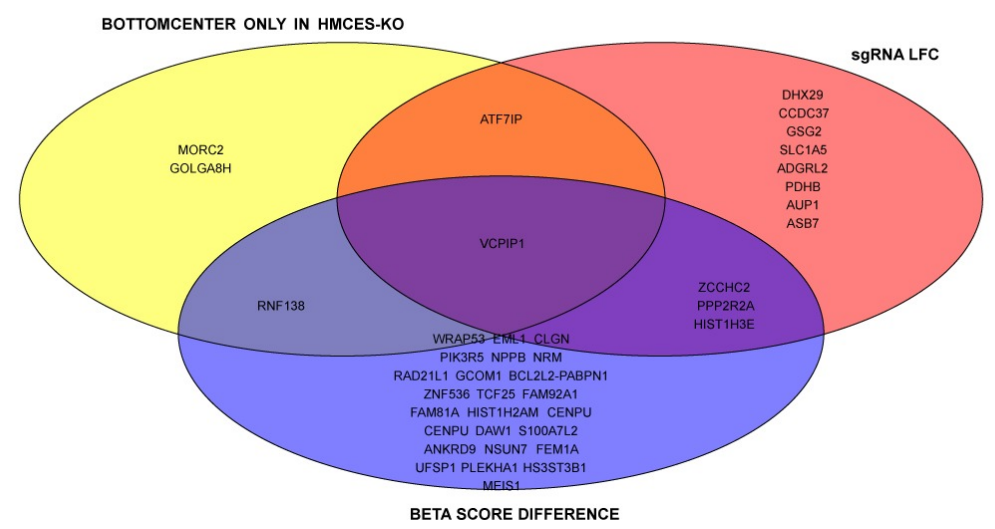

B

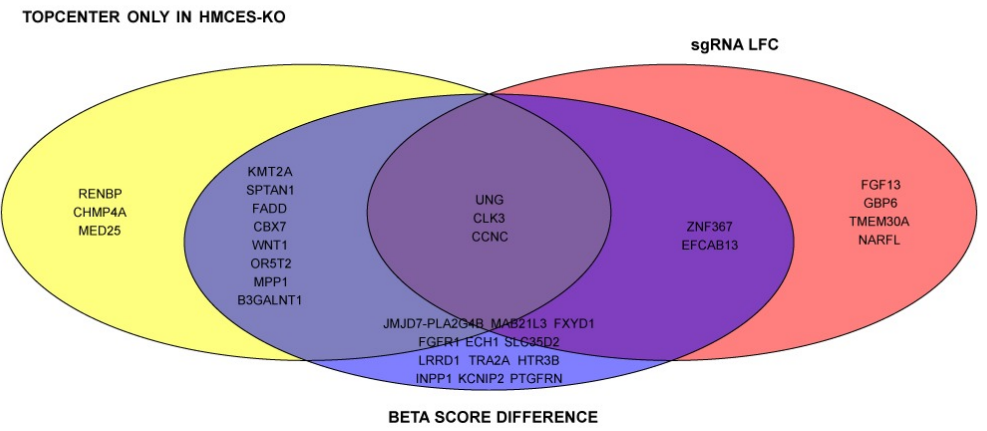

C

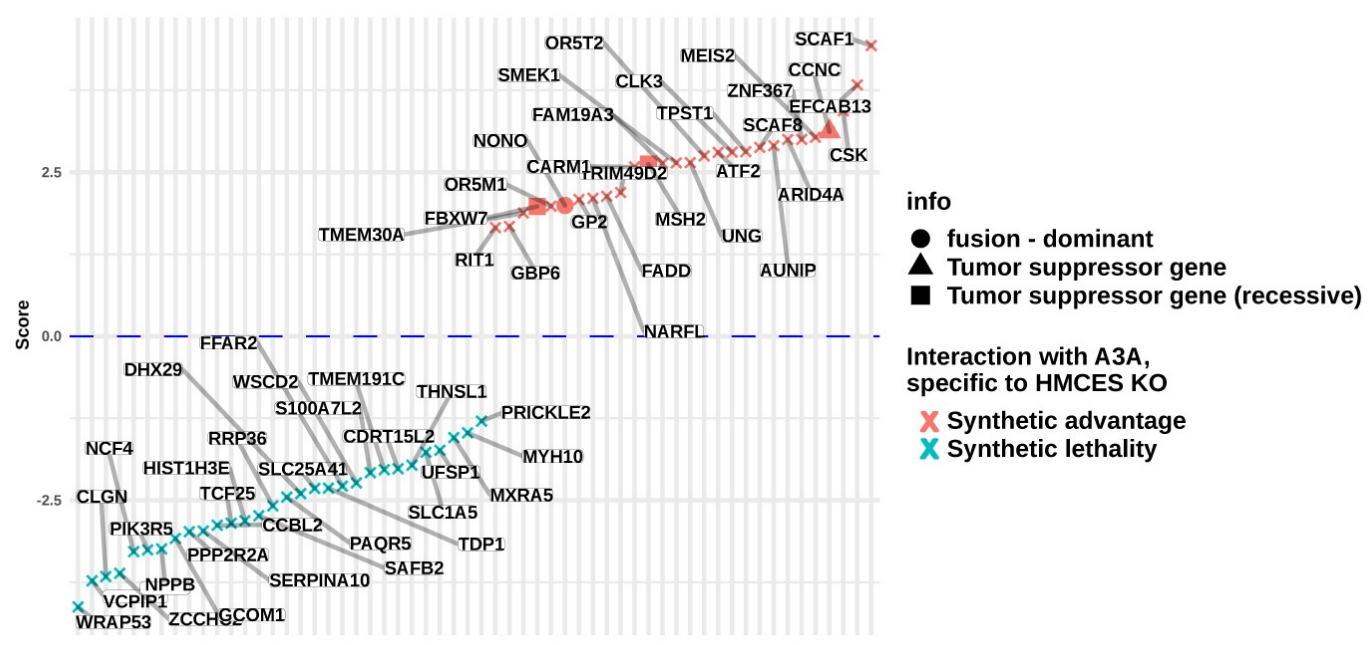

1297 S11 Fig. Genes in epistasis with A3A expression in HMCES KO cells. (A, B):

1298 Venn diagrams containing genes that are in epistasis with A3A expression (panel A,

1299 synthetic sickness/lethality, panel B, synthetic advantage) exclusively within an HMCES KO

1300 background, when applying three complementary statistical methodologies. Genes in the 
1301 red circle have a standardized sgRNA LFC <-2 (A) or >2 (B) in the four DOX versus control 1302 comparisons $\left(\mathrm{IC}_{25}-\mathrm{t} 12, \mathrm{IC}_{50}-\mathrm{t} 12, \mathrm{IC}_{25} \mathrm{t} 17\right.$, and $\left.\mathrm{IC}_{50}-\mathrm{t} 17\right)$ exclusively in HMCES KO samples. 1303 Genes in the blue circle fulfill the same criteria but using the MAGeCK-MLE standardized 1304 beta score difference, instead of the LFC. Lastly, the yellow circle contains genes whose 1305 normalized beta scores are not different from 0 in the control sample while they are 1306 significantly different from 0 (A, lower; B, higher) in the A3A-expressing sample, exclusively 1307 in an HMCES KO background: specifically, this corresponds to the "bottom-center" (A) or 1308 "top-center" (B) square of MAGeCK-FLUTE's nine-square scatterplot visualization (see 1309 panel B of S4 Fig). (C) Genes shown in panels A and B, sorted by a score calculated as the 1310 mean of the standardized sgRNA LFCs and standardized MLE beta score differences from 1311 the four DOX vs. control comparisons of HMCES KO samples, minus the mean obtained in 1312 the same way for the HMCES wt samples. Therefore, a negative score (in blue) suggests 1313 that the gene could be synthetic lethal with A3A expression in HMCES KO but not in HMCES 1314 wt (e.g. PPP2R2A), and consequently a positive score (red) suggests that the gene could 1315 have synthetic advantage with A3A expression in HMCES KO but not in HMCES wt (e.g. 1316 UNG). Triangles indicate known tumor supressor genes in Cancer Gene Census, while a 1317 circles indicate a known oncogene.

1319 See excel file.

1320 S6 Table. Gene-level data for the secondary genetic screen in HMCES-/- cells.

1322 See excel file.

1323 S7 Table. GO enrichment analysis of the secondary screening data. 


\begin{tabular}{|l|l|}
\hline $\begin{array}{l}\text { Taqman } \\
\text { Probes }\end{array}$ & \\
\hline Gen Name & Probe ID \\
\hline HMCES & Hs99999905_m1 \\
\hline GAPDH & Hs99999905_m1 \\
\hline $\begin{array}{l}\text { Oligonucleoti } \\
\text { des }\end{array}$ & \\
\hline $\begin{array}{l}\text { Gene Name } \\
\text { APOBEC3A } \\
\text { Forward }\end{array}$ & Sequence (5'-3') / Sets \\
\hline $\begin{array}{l}\text { APOBEC3A } \\
\text { Reverse }\end{array}$ & TTAGCCTGGTTGTGTAGAAAGC* \\
\hline $\begin{array}{l}\text { GAPDH } \\
\text { Forward }\end{array}$ & AGCCACATCGCTCAGACAC \\
\hline $\begin{array}{l}\text { GAPDH } \\
\text { Reverse }\end{array}$ & GCCCAATACGACCAAATCC \\
\hline $\begin{array}{l}\text { PCR1 } \\
\text { Forward }\end{array}$ & $\begin{array}{l}\text { AATGATACGGCGACCACCGAGATCTCGATTTCTTGGCTTTATATATCT } \\
\text { TGTGAAAGGACG }\end{array}$ \\
\hline $\begin{array}{l}\text { PCR1 } \\
\text { Reverse }\end{array}$ & $\begin{array}{l}\text { GTGACTGGAGTTCAGACGTGTGCTCTTCCGATCTCCAATTCCCACTC } \\
\text { CTTCAAGACCT }\end{array}$ \\
\hline $\begin{array}{l}\text { Illumina } \\
\text { Forward } \\
\text { (PCR2) }\end{array}$ & AATGATACGGCGACCACCGAGATCT \\
\hline $\begin{array}{l}\text { NEBNext } \\
\text { Multiplex } \\
\text { Oligos } \\
\text { Reverse) } \\
\text { PCR2) }\end{array}$ & E7335S (Set 1), E7500S (Set 2), E7710S (Set 3) i E7730S (Set 4) \\
\hline $\begin{array}{l}\text { Custom } \\
\text { Sequencing } \\
\text { Primer }\end{array}$ & CGATTTCTTGGCTTTATATATCTTGTGGAAAGGACGAAACACCG \\
\hline
\end{tabular}

S8 Table. List of qRT-PCR primers (Taqman/Oligonucleotides) and PCR primers for

1327 library amplification and NGS. *Primer sequence obtained from PrimerBank[84]. 